\title{
تطوير منهج تعليم اللغة العربية
}

بجامعة سونان غونونج جاتي الإسلامية الحكومية باندونج

عزالدين مصطفى

ملخص

ينطلق هذا البحث من أن نتائج تعليم اللغة العربية بجامعة سونان غونونج جاتي الإسلامية الحكومية باندونج لم تصل إلى الهدف المنشود. تحقق تلك النتائج الضعيفة من اختبار كفاءة لغوية للطلبة الذين قد قاموا بدراسة اللغة العربية بهذه الجامعة من مختلف الأقسام للعلوم الدينية. وهذا الواقع يحتاج إلى لئل الكشف عن المنهج النموذجي المناسب المستخدم لترقية نوعية الخريجين في مهارة اللغة العربية، وهو

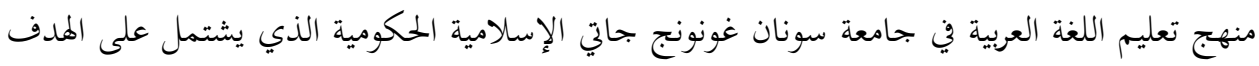
المنشود، والمختوى، وعملية التعلم والتعليم، وتقويمها. وطريقة البحث المستخدمة في هذه الدراسة هي لئي البحث والتنمية Research and Development، ذلك لأن البحث يركز إلى تطوير منهج تعليم اللغة وله العربية في جامعة سونان غونونج جاتي الإسلامية الحكومية. المصطلحات الرئيسية: التطوير، المنهج، التعليم، اللغة العربية.

\section{ABSTRACT}

This study is based on the reality that learning process of Arabic in UIN Sunan Gunung Djati Bandung has not been able to reach the expected result. It is indicated in the result of language proficiency test of the students who learn Arabic in a number of departments and programs in UIN SGD Bandung. Therefore, it is necessary that appropriate model of curriculum be found as a solution to improve the quality of the graduates in mastery Arabic skills; that is, the curriculum for teaching learning Arabic that facilitates students to achieve the goals, content standard, teaching learning process, and evaluation system. This study utilizes Research and Development method, since it focuses on curriculum development of Arabic in UIN SGD Bandung.

Keywords: Development, Curriculum, Learning Arabic 
كانت كفاءة الطلاب في اللغة العربية في جامعة سونان غونونج جاتي الإسلامية الحكومية

باندونج لا تزال ضعيفة، وهذا يتضح في الملاحظة من الدراسات الأولية لخمسين رسالة جامعية من

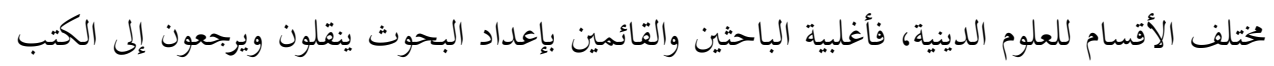

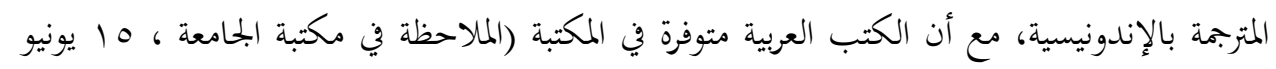

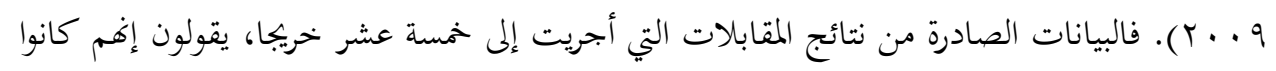

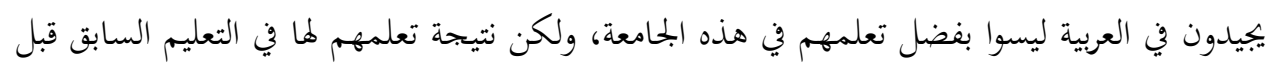

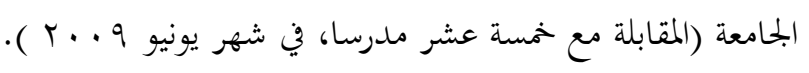

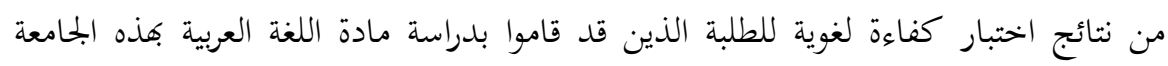

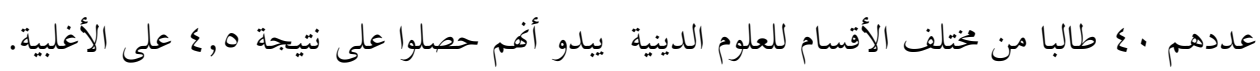

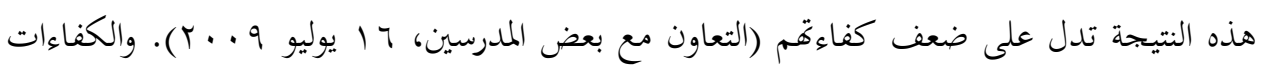

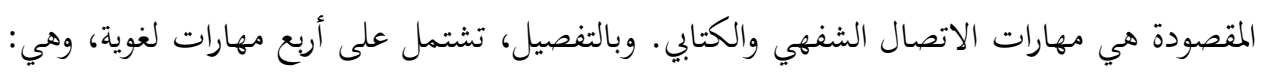

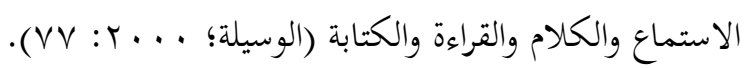
إن الجهود المبذولة لترقية الكفاءة في اللغة العربية ستكون مستمرة ولن تتوقف، وهذا يتم مثلا من خلال تعيين مؤسسة خاصة لتعليم اللغة أو إنشاء معهد اللغة العربية في كل جامعة إسلامية، ومن ثم جعله كشرط للحصول على الشهادة الجامعية، ويجب على كل طالب أن يكون له شهادة في اللغة الأجنبية.

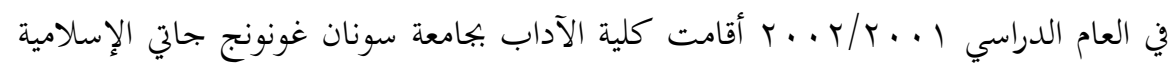
الحكومية برنابحا لتعليم اللغة العربية بشكل مكثف لهام يوميا كإعداد لدخول الجامعة (مرحلة ما قبل

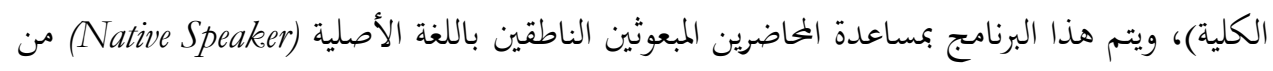

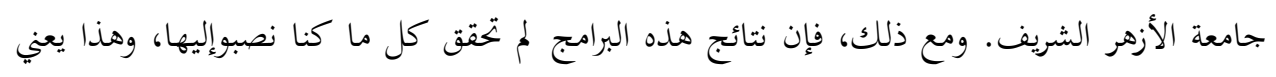

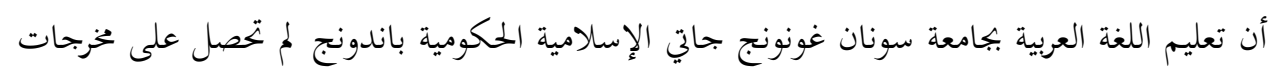
ذات كفاءة عالية في المواد الدراسية لمهارات اللغة العربية.

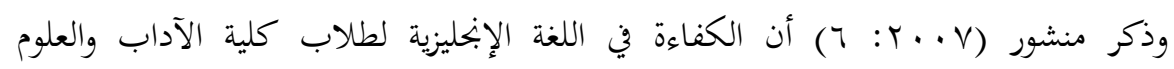

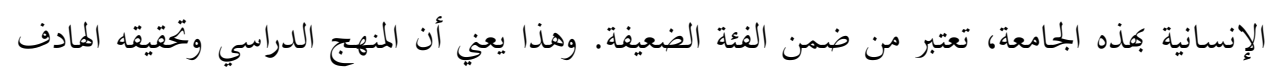

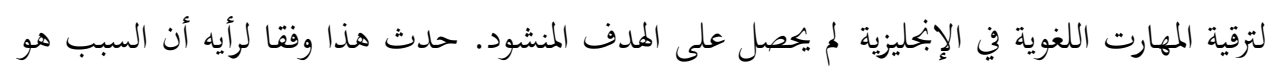


لعدم المدرسين وعدم الإتقان لعملية التدريس فيها. وفي بحال تعلم اللغة العربية، حاول عبد الرحمن

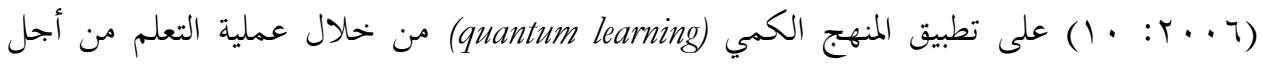
تحسين برنامج التعليم والإنحاز فيه والنتيجة فيها لم تزل ضعيف لمعيفة أيضا. ومن بعض نتائج البحوث المشار إليها، يمكن الاستنتاج أن تعليم اللغة الأجنبية (العربية

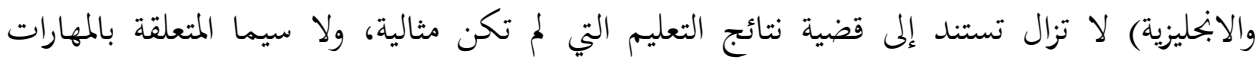

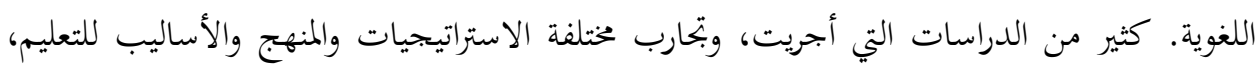

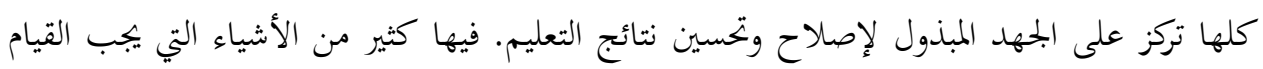

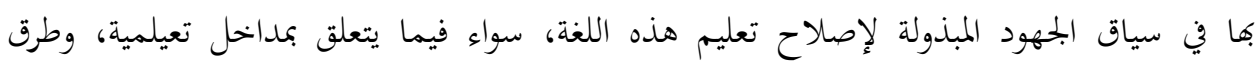

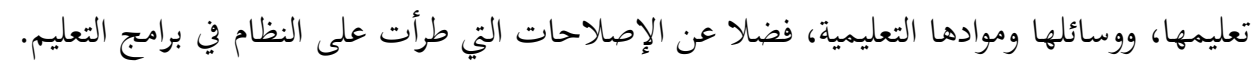

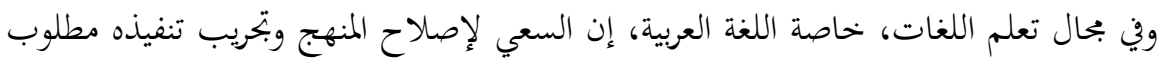

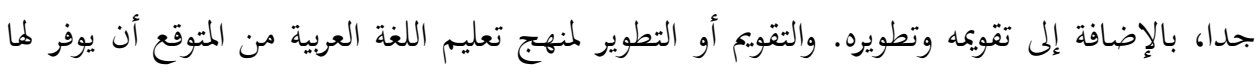

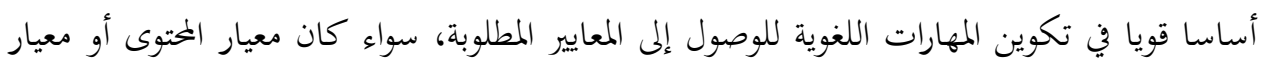

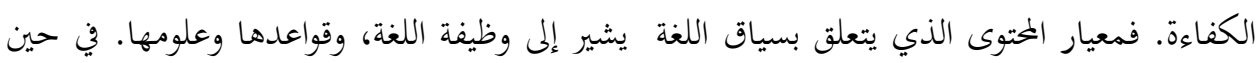
أن معيار الكفاءة الذي يتعلق بالقدرة على المهارات اللغوية تستند إلى الكفاءات المتوقعة.

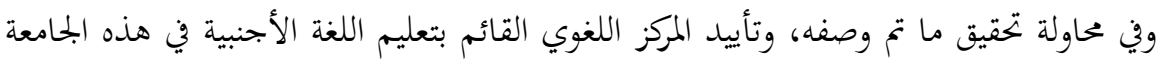
ينبغي أن تكون لها دراسة خاصة تعالج هذه المشكلة. والمشكلة الرئيسية هي ترتكز على تنفيذ المنهج

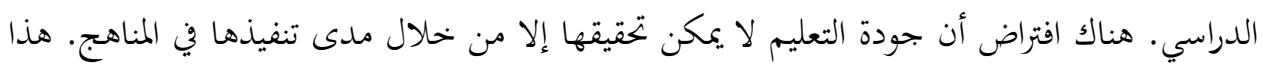

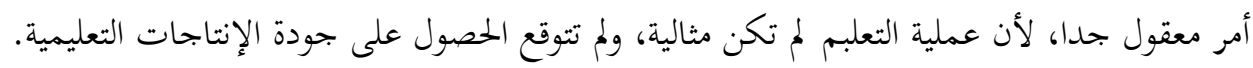

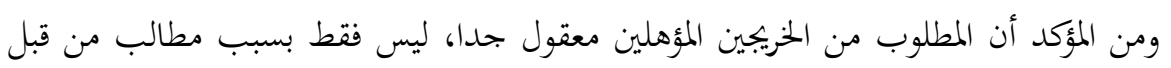
نظام التعليم الوطني فيما يتعلق بمعايير الجودة، ولكن يتعلق بمتطلبات السوق التي توفر الفرص التنافسية

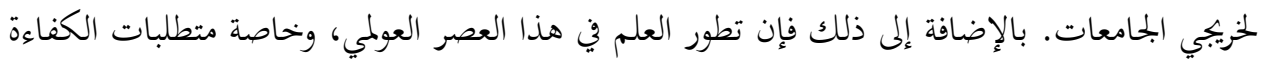
على اللغات الاجنبية أمر مهم، من أجل الوصول إلى بحموعة متنوعة من المعلومات المفيدة.

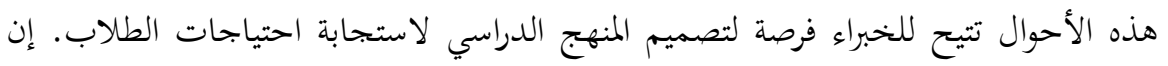

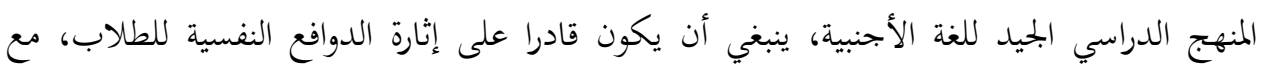

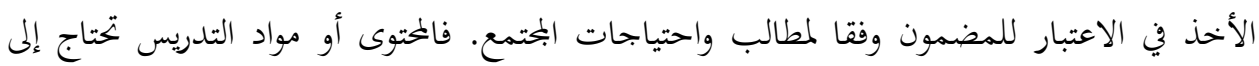
صياغة جديدة مثيرة بحيث يمكن للطلاب تطبيقها في مختلف ميادين النشاط فعالا، تحدثا وكتابة. 
نظرا لمتطلبات المؤهلات المتزايدة في البيئة التعليمية خاصة، فكل أقسام الدراسة بأكملها من

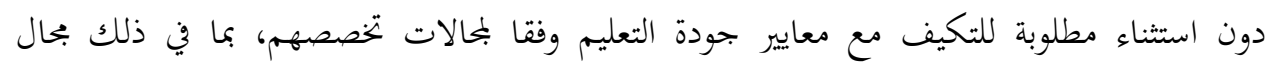

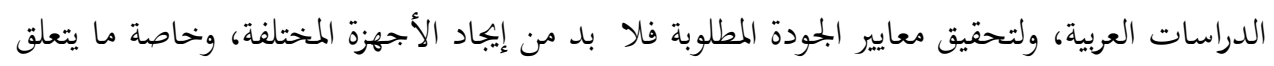
بعملية التعلم والتعليم.

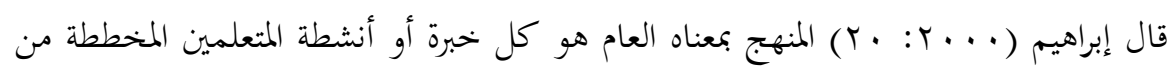

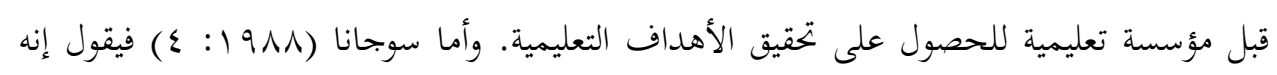
كل خبرة التعلم التي تلقاها الطلاب، وتؤثر على تنمية سلوكهم.

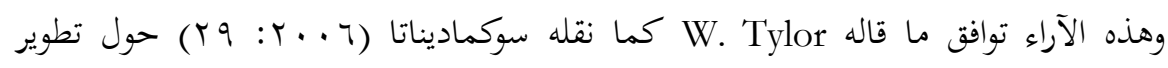

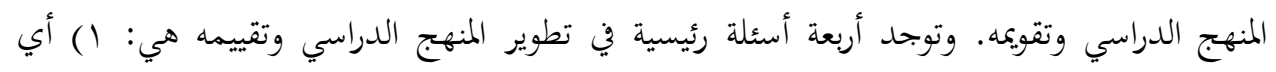

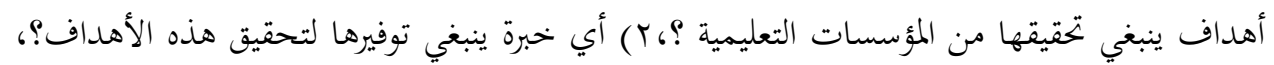

r

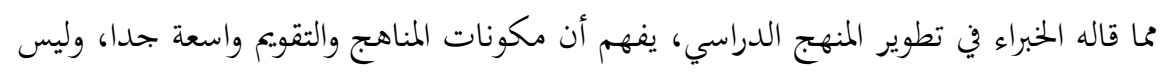
بحرد تقويم نتائج التعلم وعملية التعلم، بل تشمل أيضا تصميمه وتنفيذه، وكفاءة المعلمين والمحاضرين

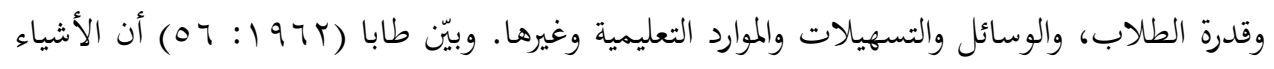

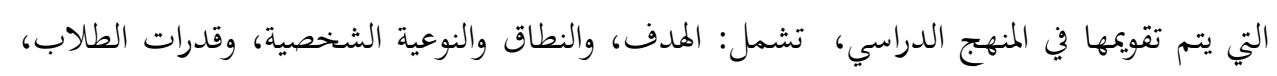
والأهمية النسبية لموضوع مختلف، وإلى أي مدى يتم تنفيذ الأهداف، والمعدات والمواد وهلم جرا. ليكون للمنهج الدراسي المصمم أثر فعال ينبغي أن ينطلق من نظرية علم النفس لأن نتائج

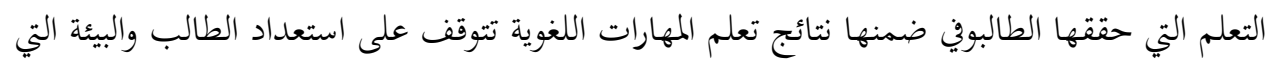

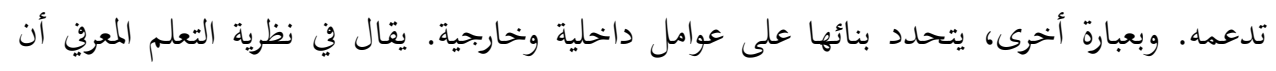
سلوك الانسان هو وظيفة الكائن الحي وبيئته التي تبين مدى أهمية هذين العاملين في تعلم الإنسان.

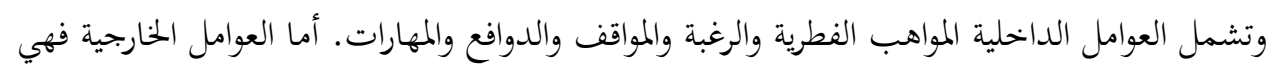
خارج نفس الفرد، و تنبع من البيئات الثلاث الرئيسية، وهي الأسرة والمدرسة والمختمع. 
في عملية التعليم في المدارس والبيئة المدرسية مثل المنهج الدراسي، وعملية التعليم والتعلم، والمعلمين، والمرافق والبنية التحتية، والخدمات المدرسية، والجو الدراسي، وانضباط التعلم ونظام المدارس

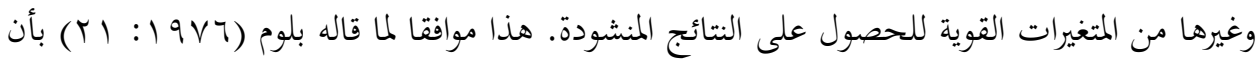
هناك ثلاثة متغيرات رئيسية في نظرية التعلم وهي الخصائص الفردية، وجودة التعليم ونتائج التعلم. هذه المتغيرات الثلاثة مرتبطة ببعضها البعض. النتائج التي يمققها الطالب في دراسته تؤثر فيها الخصائص

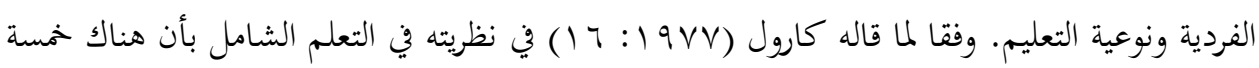
عوامل تحدد نجاح التعلم وهي الموهبة، والوقت المتاح للدراسة، والوقت المطلوب من قبل قبل الطلاب لاستيعاب المواد التعليمية، وجودة التعليم، والاستعداد الفردي. وتعتبر موهبة الشخص وقدراته عوامل داخلية، أما نوعية التدريس والوقت المطلوب فهو عامل خارجي. نوعية التعليم باعتبارها العامل الخارجي هي في الواقع البيئة المدرسية المؤيدة للمناهج المدرسية، وعملية التعليم والتعلم، والمعلمين، والمرافق والبنية التحتية وغيرها.

العوامل الداخلية والخارجية هي مككونات المنهاج الدراسي الذي يتم تنفيذه فعليا. فالعامل الداخلي قد أثرت فيه النظرية المعرفية في علم النفس التي تنص على أن الطالب هو المهيمن في تحديد

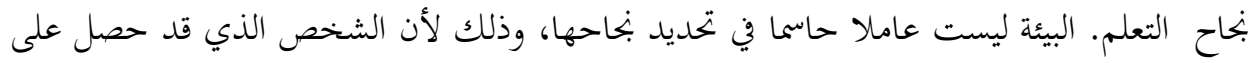
التحفيز من البيئة سوف يقوم باختيار الأشياء المناسبة مع مصالحه واحتياجاته ويفسرها ويربطها بالخبرة السابقة، ثم يختار أنسب رد. أما العوامل الخارجية فيدعمها مذهب النظرية السلوكية التي توضح أن

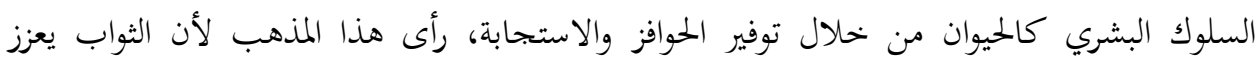
العلاقة بين التحفيز والاستجابة، وعلى العكس العقاب يضعفها. وبالتالي، تعلم اللغة هو عملية اتصالية بين الأحداث الجسدية والعقلية. وأقوى أحداث العلاقة وأكثرها ستحصل على نتائج أفضل للتعلم.

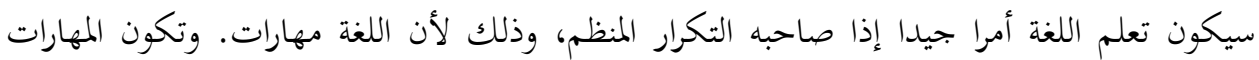
جيدة إذا كانت هناك ممارسة جيدة ومنتظمة.

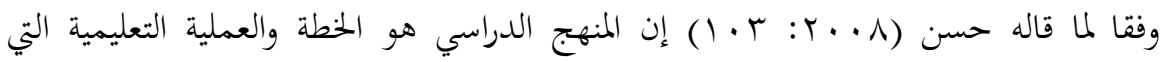

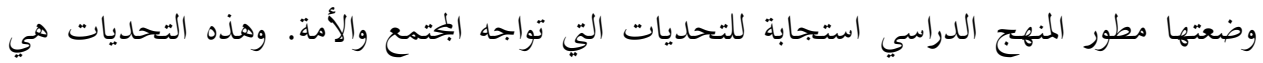

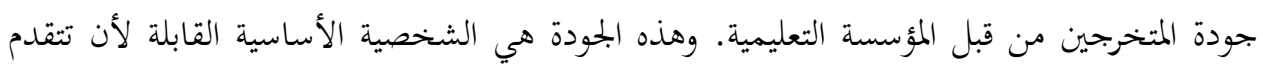
ويمكن استخدامها في حياة الإنسان المتعلم لتطوير نفسه بوصفه عضوا في المجتمع. لذا، ينبغي أن يتجه المنهج الدراسي إلى المستقبل استنادا إلى الظروف الحالية . 
والواقع، أن التحدي هو نتيجة تحليل المشاكل التي تنشأ في البحتمع بالمقارنة مع ظروف مثالية

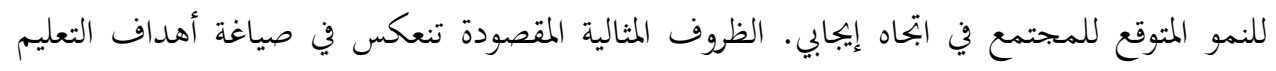
الوطني. وبعبارة أخرى، إن التحدي هو نتيجة تقويم حالة البمتمع من الصفات الإنسانية التي يتطلبها

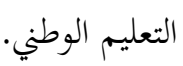

استجابة لهذه التحديات يقرر الهدف المنشود من قبل المؤسسة حسب المستوى وتخصص التربية. في إندونيسيا سميت الأهداف المنشودة التي سبق ذكرها معايير وطنية للتعليم منذ تطبيق القانون

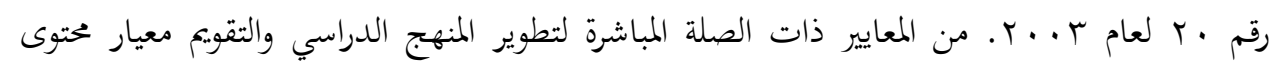

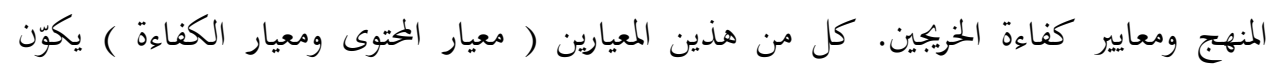

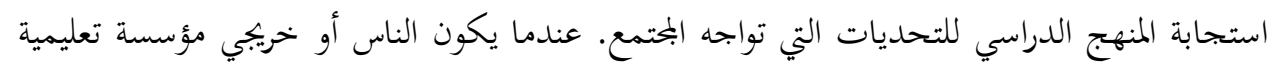

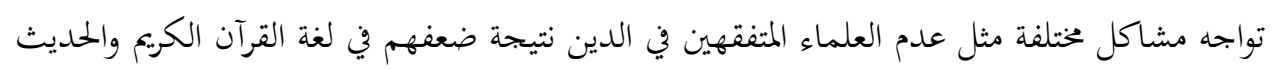

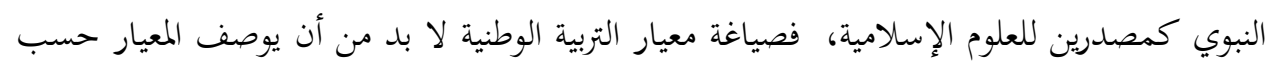
المواصفات التي سبق ذكرها. المعيار الوطني يمكن أن يزاد أيضا بالمعيار المحلي إجابة عن تحديات المختمع المحلي (القرية،

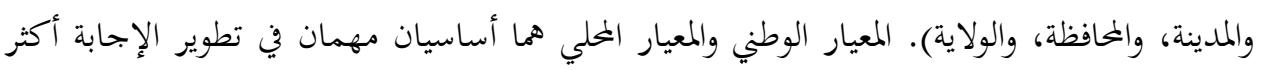

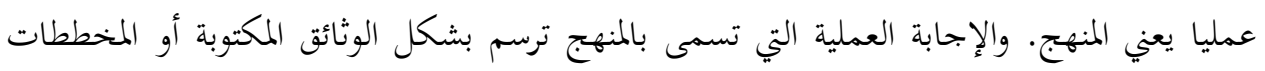

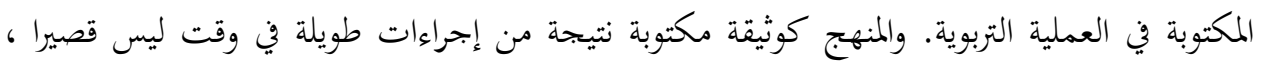

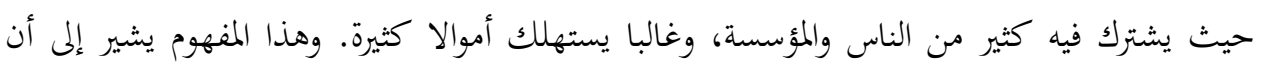

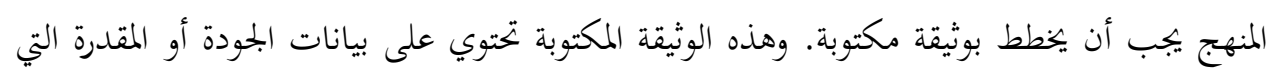

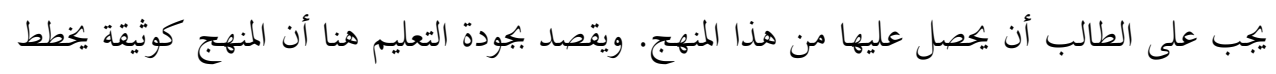
لها لجودة ثمرة التعلم التي يجب على الطالب أن يجصل عليها، وجودة المواد التعليمية وجودة عملية التعلم والتعليم التي يجب أن يشترك فيها الطالب. وتنفيذا لما رُسم في المنهج بصورة الوثيقة المكتوبة تحققت الخبرة التي جهزتحا مؤسسة تعليمية

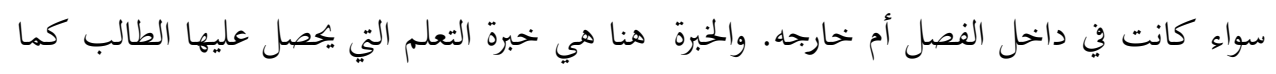
هو خخطط له من قبل المدرس بصورة وثيقة مكتوبة. وهذه الخبرة تأثير مباشر للوثيقة المكتوبة التي يطورها المدرس أو الموجه وهي تسمى بالخطة الدراسية ووحدة البرنامج الدراسية. وتعطي هذه الخبرة التعليمية أثرا مباشرا لنتائج التعلم. 
في التعريف السابق هناك جوانب لم تكن واضحة في اللفظ، ولكنها توجد ضمنيا بأن تطوير

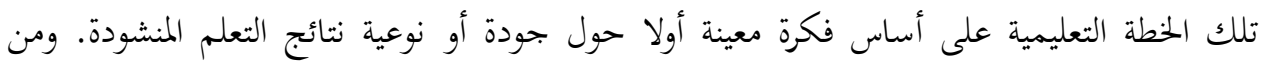

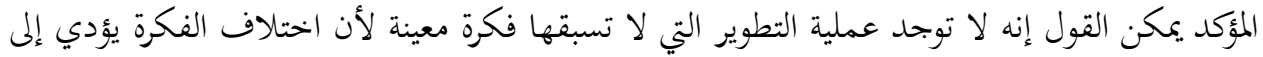
الاختلاف في المنهج المطلوب، سواء كان للوثائق أم لخبرة التعلم. وهذا الرأى منطلق بما قاله أوليفا

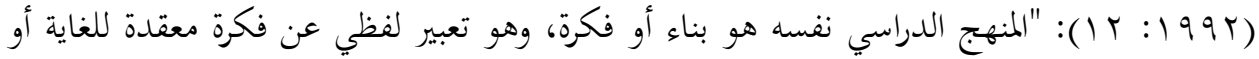
بحموعة من الأفكار".

لمزيد من الإيضاح، توصف جميع عمليات التقويم وتطوير المنهج فيما يلي:

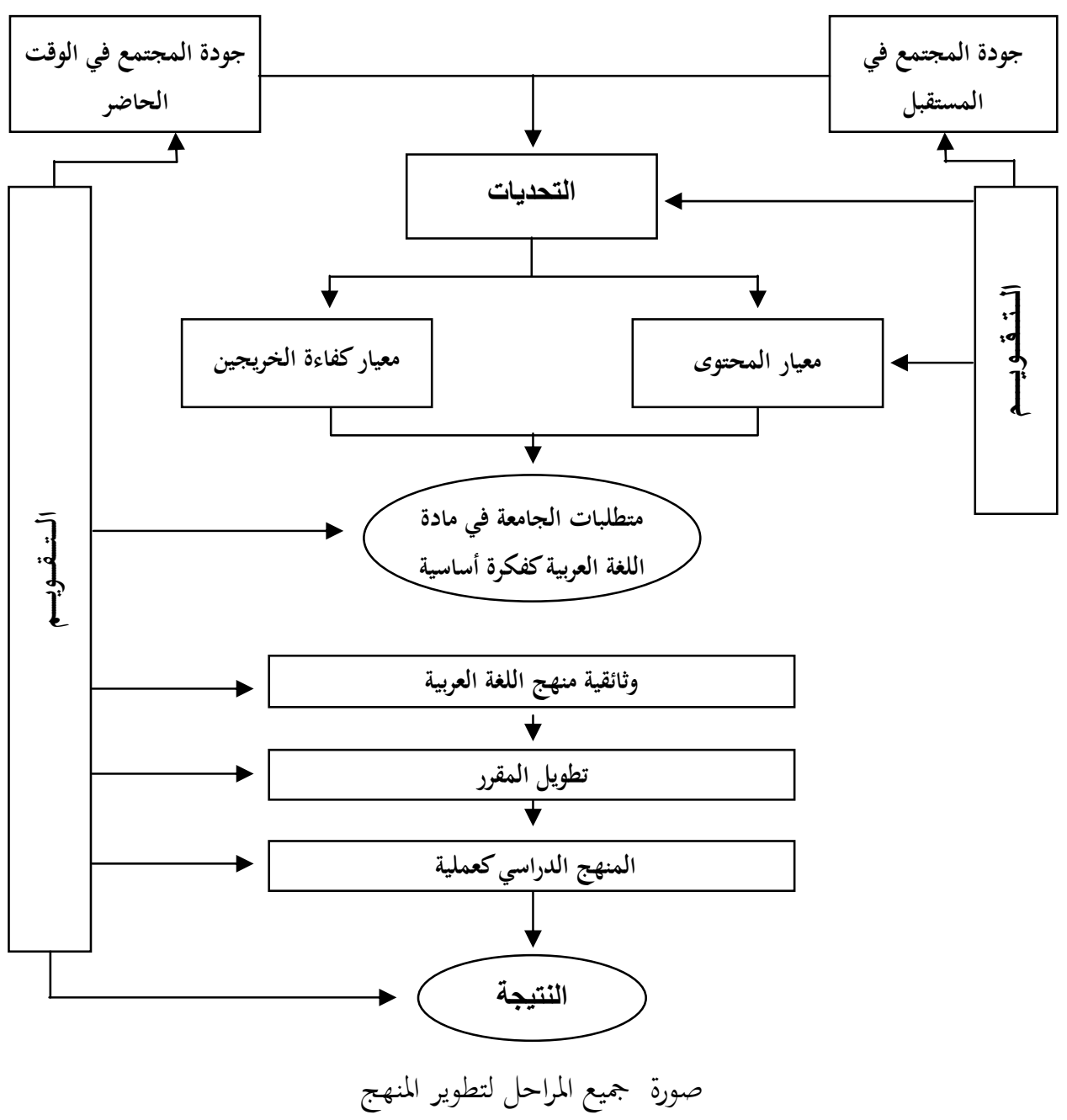




\section{تحليل تنفيذ منهج تعليم اللغة العربية حاليا في جامعة سونان جونج جاتي الإسلامية الحكومية}

لمعرفة تنفيذ منهج تعليم اللغة العربية حاليا في هذه الجامعة يعرض تحليل نتائج الدراسة

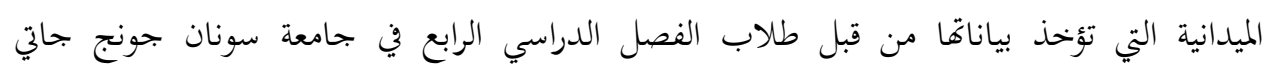

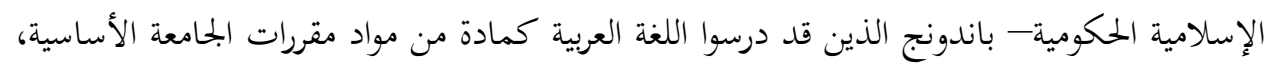
وكذلك من مدرسي اللغة العربية الذين قد شاركوا مباشرة في تنفيذ هذه المناهج الدراسية.

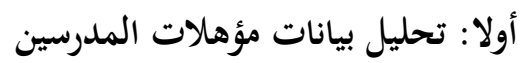
أ- جانب شهادتهم الأخيرة

أشارت النتائج النهائية للبحث الميدائ الذي تم الحصول على بياناتا من المدرسين، أن معظم

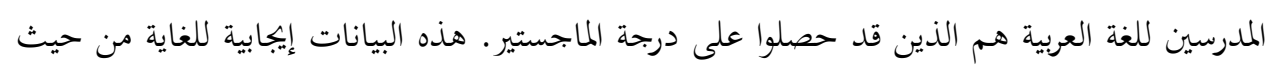

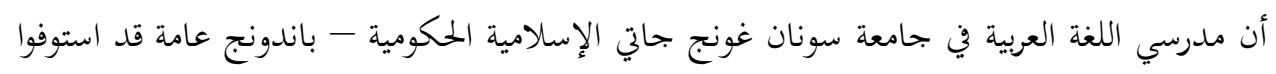

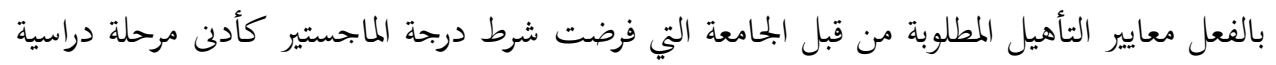
لكل من يقوم بالتدريس في الجحامعة على الرغم من تخصصات مختلفة.

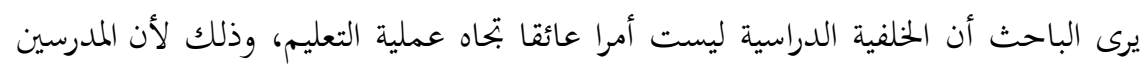

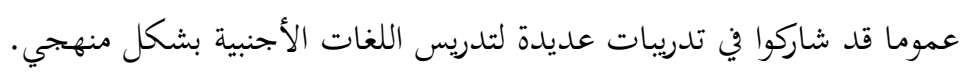

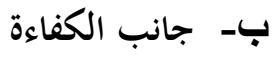

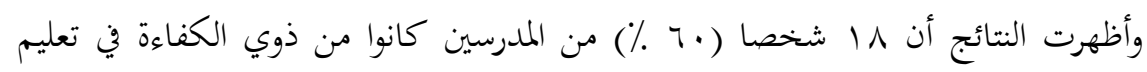

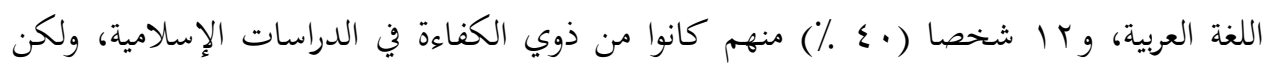

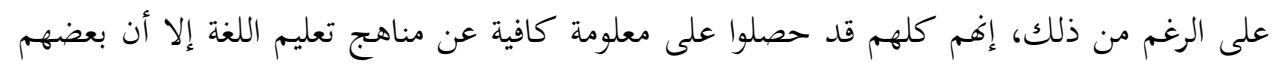
لم تكن لديهم مهارة كافية في اللغة العربية وهي مهارة التحدث واتمبم والكتابة.

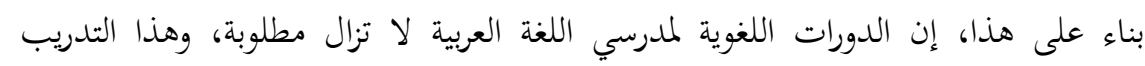
اللغوي لا ينحصر موضوعه على مناهج التعليم فحسب ولكن يحتوي أيضا على المضمون، لأن الخبرة

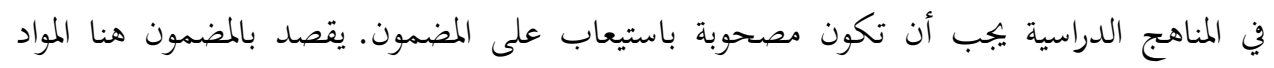

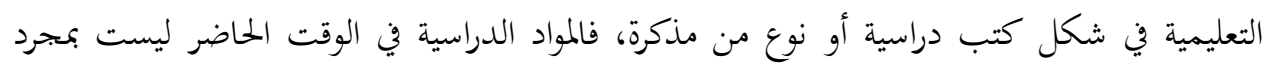
مواد اللغة العربية الفصحى السائدة في الكتب العلمية، ولكن تناولت أيضا المفردات الحديثة المنتشرة في

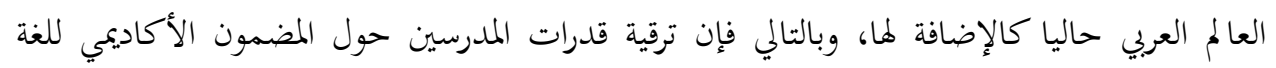


العربية الحديثة أمر ضروري وغير قابل للتفاوت، وفي المستقبل سيتمكن للطلاب من التمتع بتعلم اللغة العربية في جامعة جامعة سونان غونج جاتي الإسلامية الحكومية - باندونج.

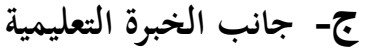

وأظهرت النتائج أن مدرسي اللغة العربية في جامعة سونان غونج جاتي الإسلامية الحكومية -

باندونج بصفة عامة قد قاموا بعملية التدريس لمدة أكثر من ه سنوات، ومن بين هؤلاء من يدرّس التس

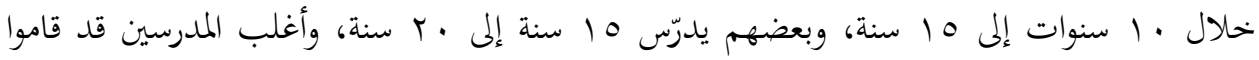
بعملية التدريس بين • ا سنوات إلى 1 إسنة، وهذا يدل على أن القائمين بتدريس اللغة العربية في

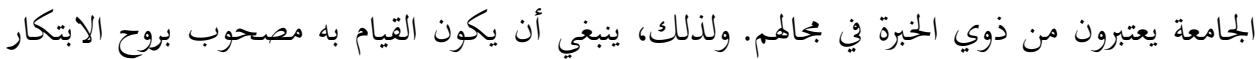

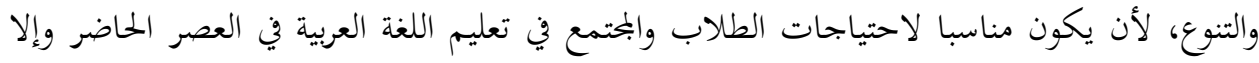
سيكون راكدا في بحال التعليم.

$$
\text { أ- تحليا- تحليل مكونات المنهج الدراسي }
$$

كشفت نتيجة البحث الميداني أن الهدف من تعليم اللغة العربية في الجامعة بجرد توجيه الطلاب

لفهم قواعد اللغة العربية ومهارة قراءة الكتب. ويرى الباحث أن هذا الهدف قد تأثر نوعا ما بأهداف تعليم اللغة العربية في المعاهد والمدارس الإسلامية المنتشرة في أنحاء البلاد، حيث أن الطلاب فيها وتهاء

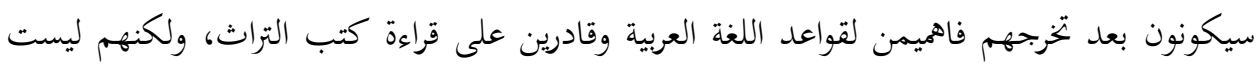
لديهم مهارة في التحدث والكتابة.

وهناك أراء الخبراء في تعليم اللغة العربية، منهم كمال إبراهيم بدري (1999 1: م) حيث قال

إنه يجب التمييز بين تدريس اللغة والتدريس عن اللغة، فتدريس اللغة يقصد منه تدريس استخدام اللغة الهادف إلى تطوير مهارات اللغة الأربع: الاستماع والتحدث والقراءة والكتابة، بينما التدريس عن اللغة يقصد منه تدريس علوم اللغة نظريا كالنحو والصرف أو قواعد اللغة.

$$
\text { ب- تحليل المواد الدراسية }
$$

وفقا لرأي الطلاب والمدرسين أن المواد الدراسية المدروسة الآن مناسبة لقدرة الطلاب، فكانت أغلب موضوعامَا تحتوي على الثقافة الإسلامية، وينصب التركيز على فهم قواعد اللغة وفهم الخطاب العربي. ولكن المواد الدراسية المناسبة لقدرة الطلاب التي تحتوي على الثقافة الإسلامية لابد أنه تكون

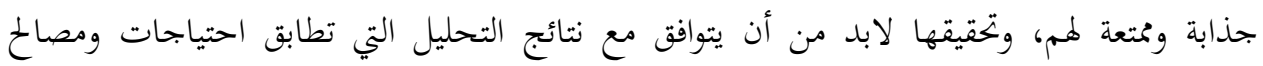


الطلاب، بناء على ذلك ينبغي أن يكون القائم بتطويرالمناهج الدراسية يبذل جهده في اختيار المواد الدراسية المفيدة للطلاب في الحاضر والمستقبل.

\section{ج- تحليل طريقة التعليم}

ا. وفقا لآراء الطلاب والمدرسين في أن الطريقة المستخدمة في تدريس اللغة العربية هي طريقة

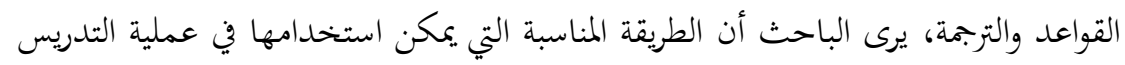

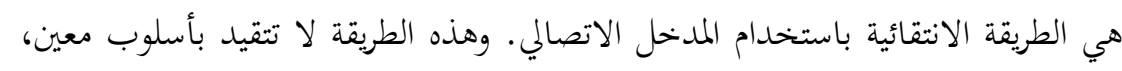

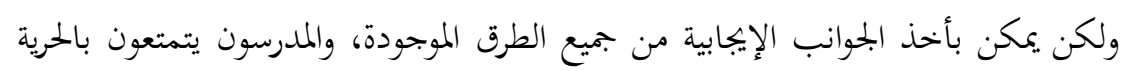

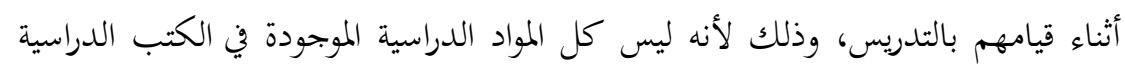

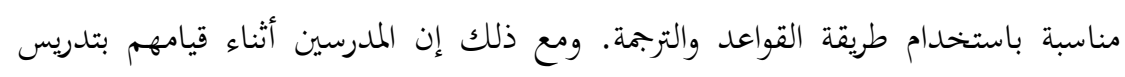

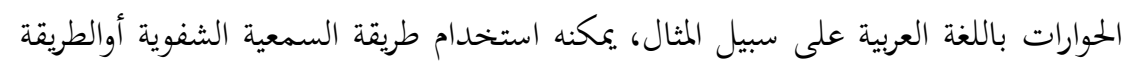
المباشرة، على الرغم من أفما تتطلبان مدرسين مؤهلين في بحال مهارات اللغة.

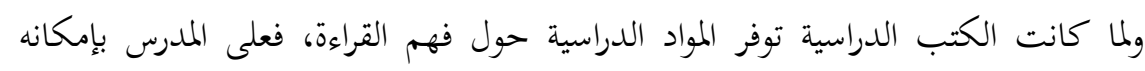
تحويل طريقة القراءة بكل سهولة، وإذا كانت المواد الدراسية حول الحوار فتحويلها إلى طريقة

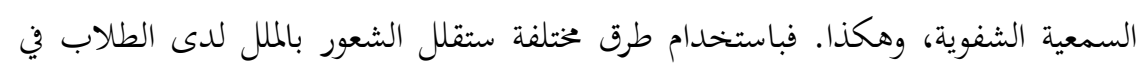

$$
\text { دراسة اللغة العربية في هذه الجامعة. }
$$

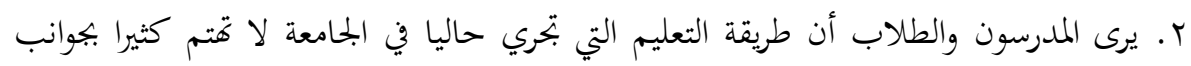

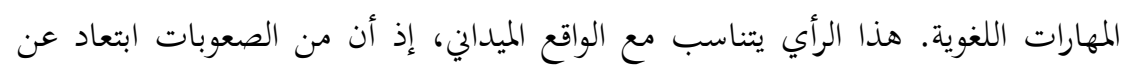

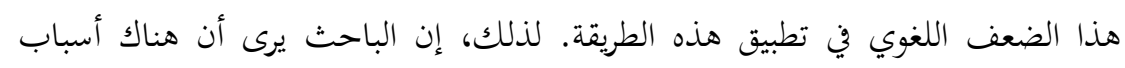
تؤدي إلى وقوع هذه الظاهرة. أ) إن أغلب المدرسين في هذه الجامعة لا يجيدون اللغة العربية حق الإجادة بمعنى أفهم

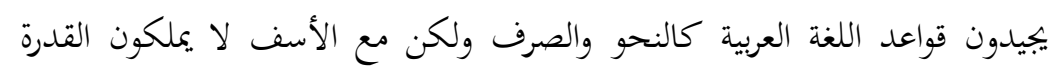

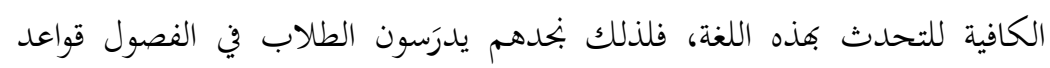

$$
\text { النحو والصرف فقط ولا يهتمون بمهارات اللغة الأربع. }
$$

ب) تصميم الكتب الدراسية يتركز على استيعاب قواعد اللغة ومهارة القراءة فقط.

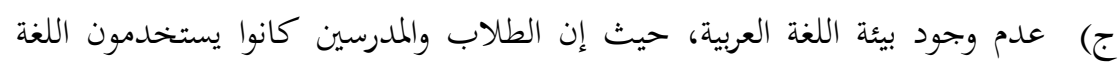

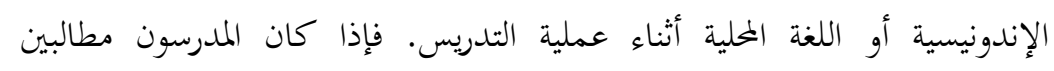


باستخدام الطريقة التي تمتم بتطوير المهارات اللغوية فينغي أن يكون تصميم الكتب الدراسية موافقا للطريقة المستخدمة لها.

r. يرى الطلاب والمدرسون أن القائمين بتدريس اللغة العربية في هذه الجامعة يستخدمون اللغة

$$
\text { الإندونيسية لغة تدريس في الفصل. }
$$

إن استخدام المدرسين للغة الإندونيسية أثناء تدريسهم اللغات الأجنبية وخاصة اللغة العربية سيعوق عملية تطورالطلاب اللغوي، لذلك فليس من الممكن أن يقوم المدرسون بتنفيذ الطريقة المباشرة في عملية التدريس بشكل كامل ويمنع استخدام اللغة الإندونيسية كلغة التدريس في بئ

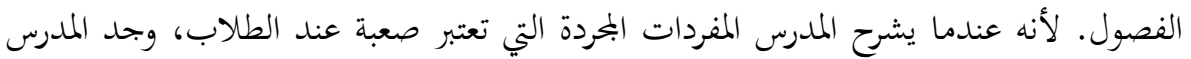
صعوبة في إحضار الوسائل التعليمية المناسبة. وفي مثل هذه الحالة يستخدم المدرس طريقة الترجمة

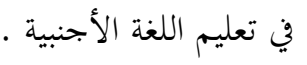

\section{د- تحليل استخدام الوسائل التعليمية}

استنادا إلى البيانات التي تؤخد من المدرسين بأن أكثر الوسائل التي استخدمها المدرسون في الميله

$$
\text { تعليم اللغة العربية هي بحرد السبورة. }
$$

رأي الباحث أن الوسائل التعليمية مهمة جدا في تعليم اللغة العربية لأها أدوات يستطيع بها المدرس بتسيد الأشياء المخردة لدى الطلاب، لاسيما في عصر تكنولوجيا الآن الذي يتميز بأجهزة متنوعة من الوسائل التعليمية، فيستطيع المدرس استخدامها في عملية تعليمية، مثل: المعمل اللغوي،

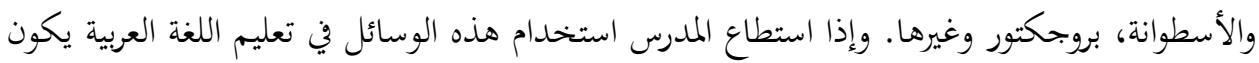

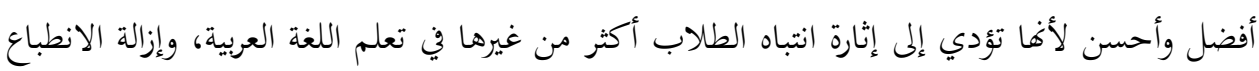
السلبي والتخلف تحاه اللغة العربية ومدرسيها، وإذا كان المدرسون في جامعة سونن غوننج جاتي الإسلامية الحكومية يستخدمون الوسائل التعليمية العصرية فلا بد كذلك أن يكون منهجها الدراسي ملائما للزمان. والمدرس لاتقل أهميته في عملية تعليمية لأنه المطور، والمقوم، والمتكيف على مدى الحياة.

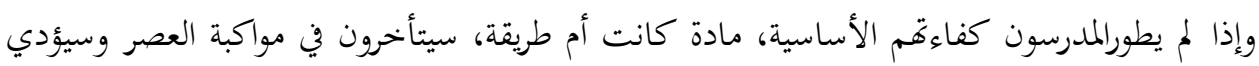
ذلك إلى سوء تعليمهم وقلة انتباه الطلاب لمادة اللغة العربية.

\section{ح- تحليل التقويم}

دلت نتائج البحث على أن أدوات التقويم التي استخدمها المدرسون تتفق مع أهداف التعليم. وهذا يدل على أن تلك الأدوات تتفق مع طريقة التقويم في هذا العصر التي ترى أن التقويم يكون لقياس 
مدى تحقق الأهداف، إذا لم تتحقق الأهداف، فيحتاج إلى تقويم أوسع نطاق، وهو تقويم البرنامج،

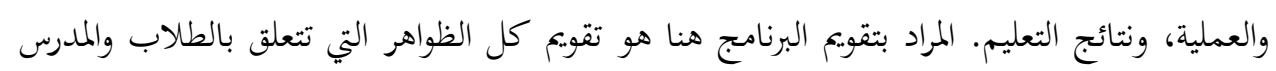

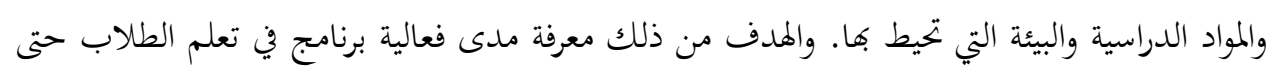

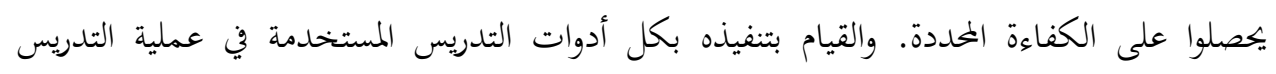
بشكل مستمر مع مراعاة احتياجات الطلاب، والخريجين.

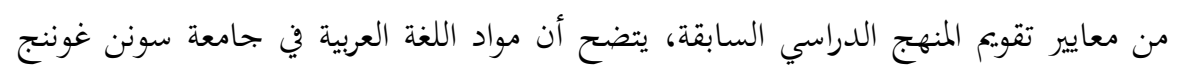

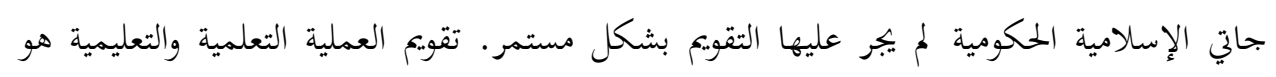

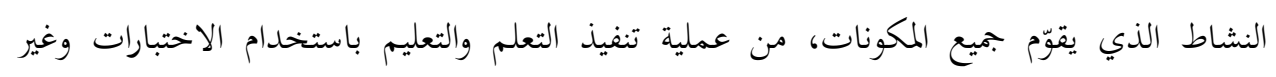
الاختبارات. يستخدم الاختبارات لتقويم نتائج تعلم الطلاب، أما غير الاختبارات (مثل الملاحظة

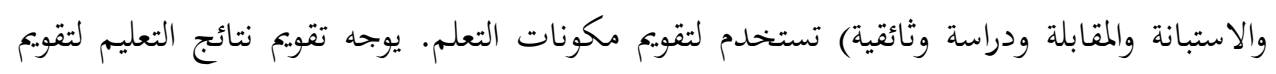

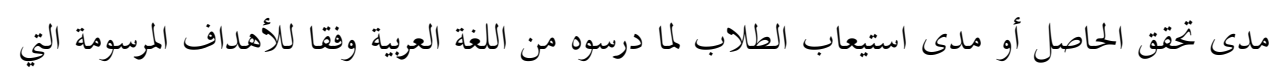

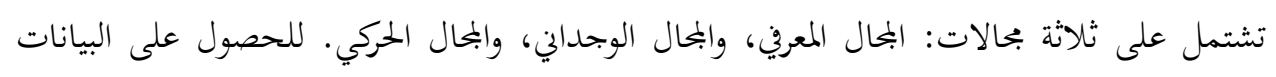

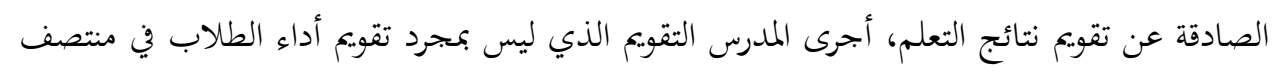

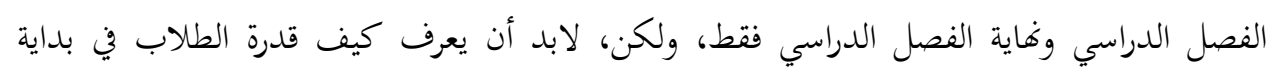
الدراسة وتطورها ونتائجها الأخيرة. طـ تحليل الحاجات

في بداية الأمر من أجل تطوير المنهج الدراسي إجراء تحليل الحاجات، أجري تحليل الحاجات

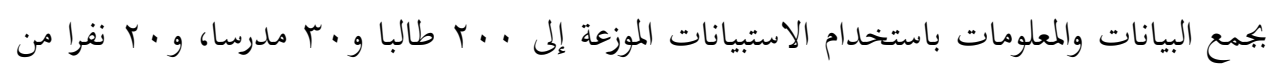

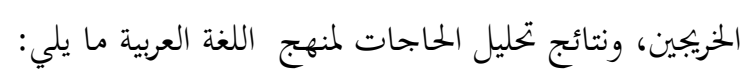
إل الأهداف التعليمية

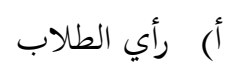

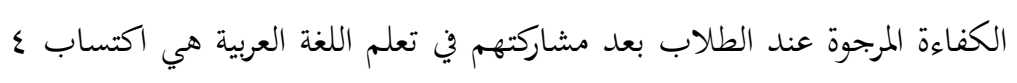

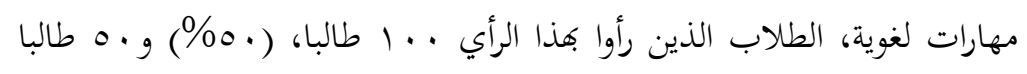

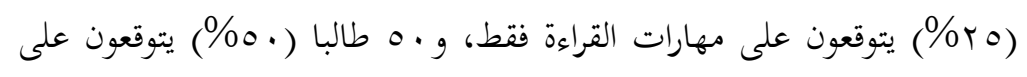
مهارات القواعد اللغوية. لمزيد من التفاصيل عن بيانات الكفاءة المحتاجة في تعليم

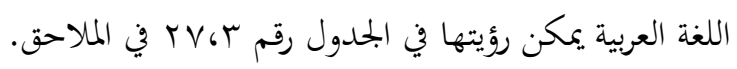


ب) بأي المدرسين

رأى المدرسون، أن الكفاءات المتوقعة بعد مشاركة الطلاب في العملية التعليمية

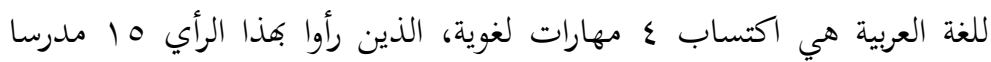

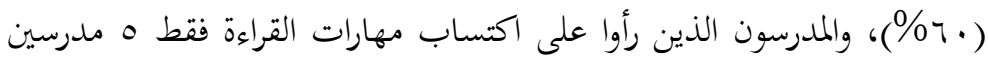

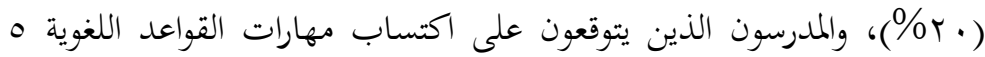

$$
\text { ج) مدرسين (· بـ\%). }
$$

بناء على نتائج الاستبانة التي وزعت على كل من الخريجين الذين عملوا في جامعة سونان غونونج جاتي الإسلامية الحكومية - باندونج وخارجها حول الحسل

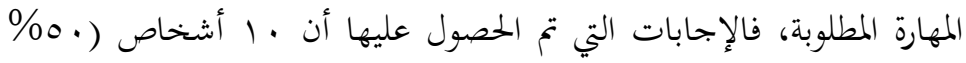

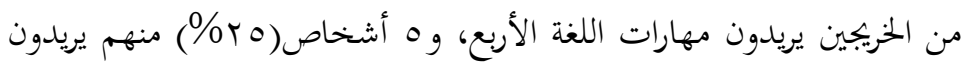

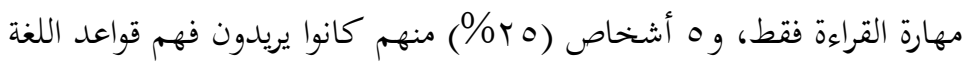

$$
\text { ومهارة القراءة. }
$$

فاستنادا إلى البيانات الواقعية تتلخص منها أن الطلاب والمدرسين والخريجين هم يريدون من تعليم اللغة العربية في هذه الجامعة استيعاب المهارات اللغوية الأربع

$$
\begin{aligned}
& \text { : الاستماع والتحدث والقراءة والكتابة. } \\
& \text { ب- المواد الدراسية } \\
& \text { أ) رأي الطلاب }
\end{aligned}
$$

ظهر من آراء الطلاب حول موضوعات المواد الدراسية لمادة اللغة العربية التي

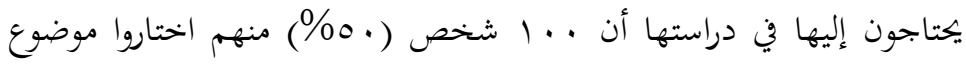

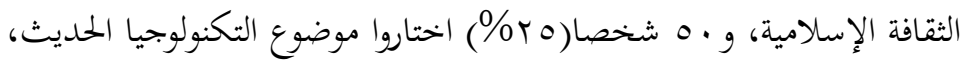

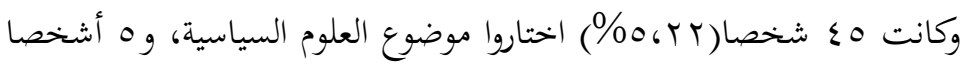
(r، (\%) اختاروا موضوع القصص الخيالية.

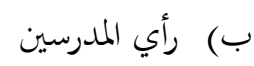

تدل البيانات على أن 10 شخصا(.0\%) من المدرسين يختارون موضوع الثقافة الاسلامية، و • 1 أشخاص(rr\%) اختاروا موضوع التكنولوجيا 
الحديث، وب أشخاص(·) (1\%) يختارون موضوع العلوم السياسية وشخصان

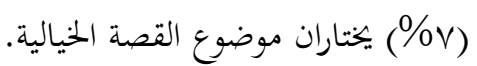
ج) رأي الخريجين

فقد تم سؤال الخريجين الذين يعملون في جامعة سونان غونونج جاتي

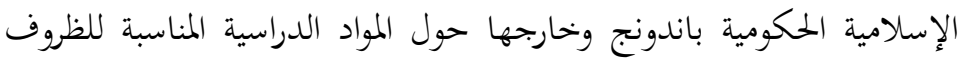

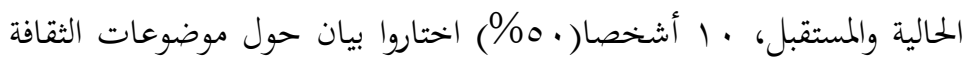

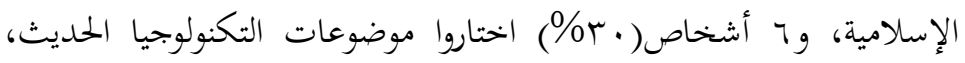

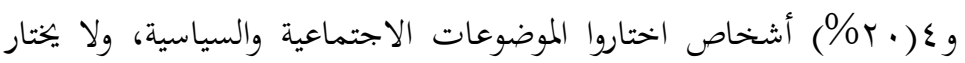
أي أحد منهم موضوعات حول القصة الخيالية.

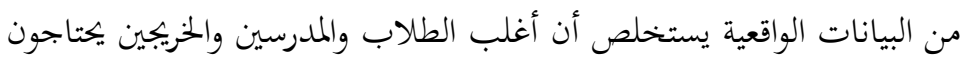

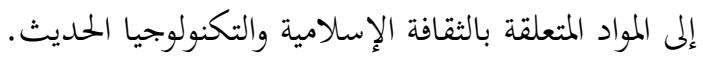

$$
\begin{aligned}
& \text { r- ـ - طريقة التعليم } \\
& \text { أ) رأي الطلاب }
\end{aligned}
$$

البيانات التي تم الحصول عليها حول الطريقة المختارة لدى الطلاب في تعليم

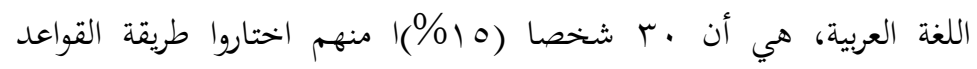

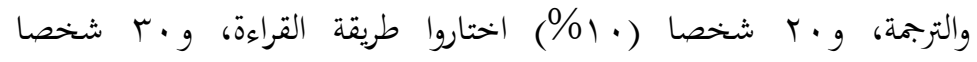

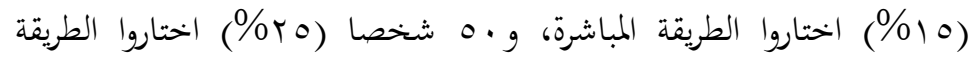

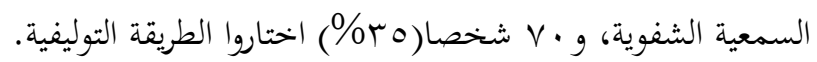

$$
\text { ب) بأي المدرسين }
$$

المدرسون الذين اختاروا طريقة القواعد والترجمة عددهمه أشخاص (V|V\%)

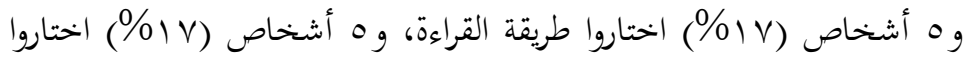
الطريقة المباشرة، وه اشخاص (V|V\%) اختاروا الطريقة السمعية الشفوية، و • ا أشخاص (rr\%) اختاروا الطريقة التوليفية. ج) رأي الخريجين

ثلاثة أشخاص (·|l\%) من الخريجين اختاروا طريقة القواعد والترجمة،

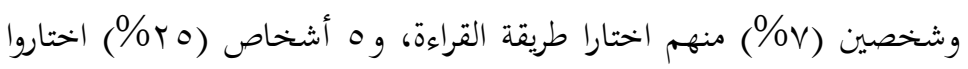


الطريقة المباشرة، و ع أشخاص (·r\%) اختاروا الطريقة السمعية الشفوية، و 7 اشخاص (·ץ\%) اختاروا الطريقة التوليفية.

البيانات الواقعية تشير إلى أن الطريقة التي يحتاجها المدرسون والطلاب والخريجون هي الطريقة التوليفية من عدة الطرق التي تميل إلى المدخل الاتصالي وهو الطريقة المباشرة والطريقة السمعية الشفوية. ع - أوسائل التعليمية

قد تم سؤاهم عن الوسائل التعليمية اللازمة لتعليم اللغة العربية، فاختار Vo

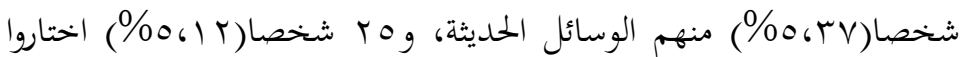
الوسائل التقليدية، و . . 1 شخصا( • 0\%) اختاروا الوسائل المتعددة.

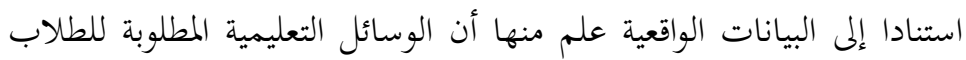
حاليا هي الوسائل المتعددة . ب) ب (أي المدرسين

عندما سئل بعض المدرسين عن رأيهم في الوسائل التعليمية الملائمة لاستخدامها عند تعليمهم اللغة العربية، فقد اختار • ا أشخاص (سب\%ة)

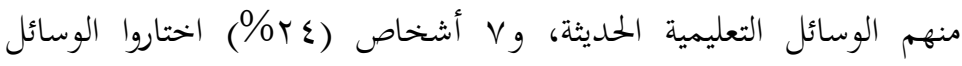
التعليمية التقليدية، وب |(T؟ع\%) شخصا اختاروا الوسائل التعليمية المتعددة.

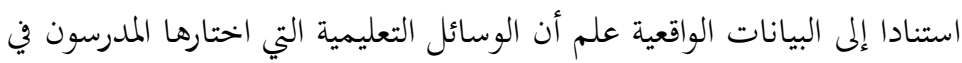
قيامهم بالتدريس هي الوسائل التعليمية المتعددة. رأي الخريجين

لا تقل أهمية الخريجين عن الفئات الأخرى حول الوسائل التعليمية التي يحتاج إليها المدرسون حاليا عند قيامهم بتدريس اللغة العربية في جامعة سونان غونونج جاتي الإسلامية الحكومية - باندونج، لأفم الذين درسوا اللغة العربية

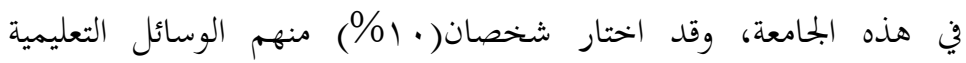

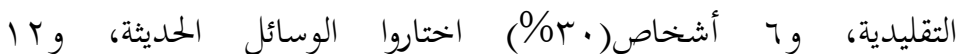
شخصا( • ب\%) اختاروا الوسائل المتعددة. 
استنادا إلى البيانات الواقعية علم أن الوسائل المطلوبة والمفضلة من قبل المدرسين والطلاب والخريجين هي الوسائل المتعددة.

$$
\text { ه- }
$$

عندما سئل عدد من الطلاب عن نموذج لتقويم عملية تعليم اللغة العربية، فقد

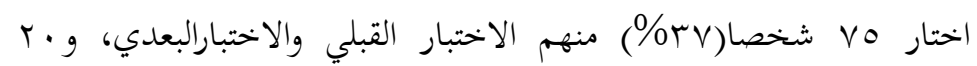

شخصا(•(\%) اختاروا اختبار نصف الفصل الدراسي والاختبار النهائي

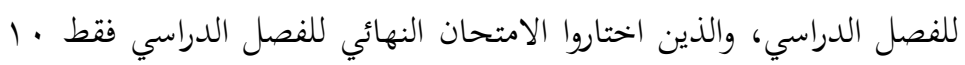

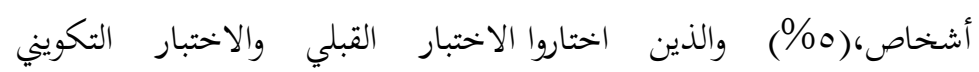

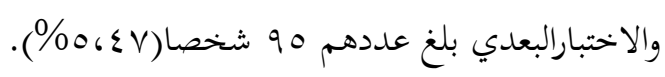

ب) بأي المدرسين

أظهر المدرسون رأيهم في نموذج التقويم اللازم على النحو التالي : اختار سار

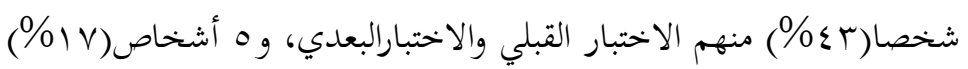

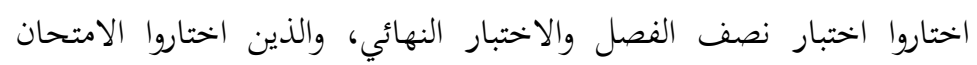

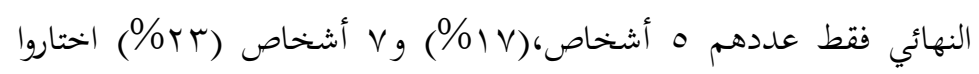
الاختبار القبلي والاختبار البعدي والاختبار التكويني والاختبارالتحصيلي.

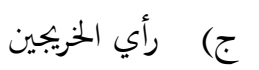

لا تقل أهمية الخريجين عن الفئات الأخرى حول التقويم السليم لعملية تعليم

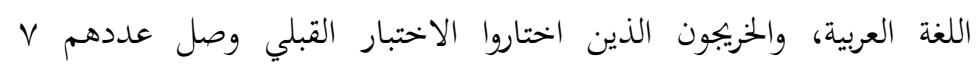

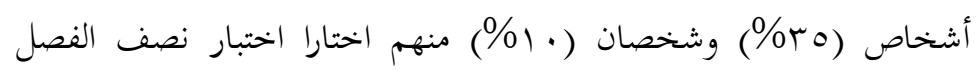

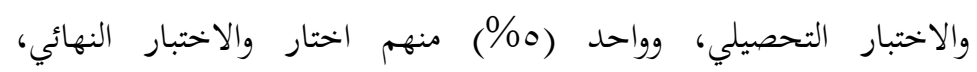

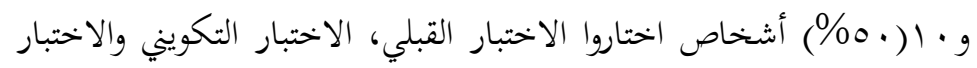
التحصيلي. استنادا إلى البيانات الواقعية تستخلص أن التقيم المطلوب من قبل المدرسين

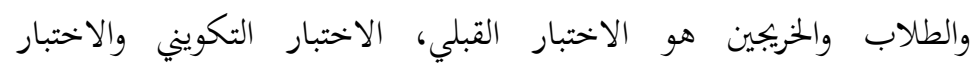
التحصيلي. 


$$
\text { نموذج منهج تعليم اللغة العربية الذي تم تطويره }
$$

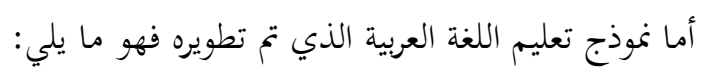

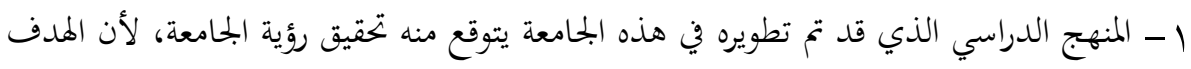
منه تمكين الطلاب من الحصول على قدرة الاتصال باللغة العربية تحدثا وكتابة مع الناطقين

$$
\text { كا وغير الناطقين بها. }
$$

r - المواد الدراسية جذابة للطلاب وذلك لأن وضعها يتم بشكل تدريجي ابتداء من البسيط إلى

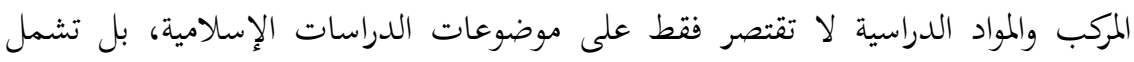

$$
\text { موضوعات التكنولوجيا الحديثة والمعاصرة. }
$$

ب- الطرائق المستخدمة متنوعة وفقا لخصائص الموضوعات أثناء قيام المدرسين بعملية التدريس.

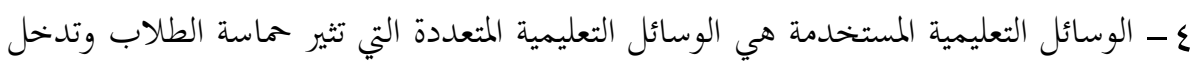

$$
\text { السرور في نفوسهم. }
$$

ه- استخدام الاختبار القبلي في بداية اللقاء ثم يعقد بعد ذلك الاختبار التحصيلي والاختبار

$$
\text { البعدي يساعد كثيرا في عملية التعليم، وتوضح نتائج دراسة الطلاب وتدريس المدرسين. }
$$

7 - دراسة اللغات الأجنبية تتطلب تخصيص الوقت كافيا، والكثافة العالية. وكلما ارتفعت كثافة دئة

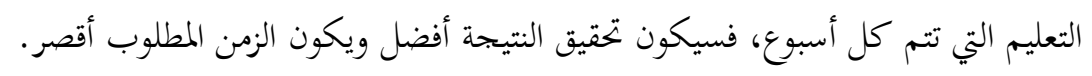

\section{تفسير نتائج التجريب

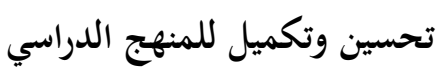

يكون تطوير منهج اللغة العربية في جامعة سونان غونونج جاتي الإسلامية الحكومية باندونج من خلال مناقشة المجموعة المركزة (FGD))، وبتربة الخبرة، التجريب في بحموعة محددة، والتجريب في بحموعة موسعة، والتحقق من صحة التجريب. من خلال التطوير التجريب تظهر النتائج بأن المنهج يجب ولئ إصلاحه وتحسينه في جميع عناصر

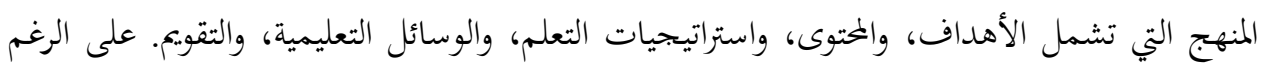

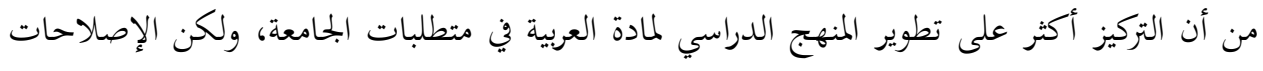

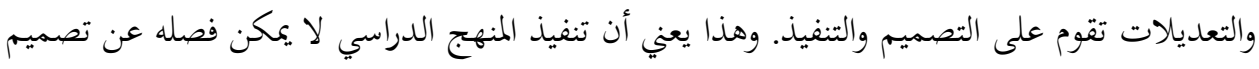


جيد ومنظم، له علاقة وثيقة بين مكونات تصميم البرنامج التي تتألف من: الأهداف والمحتوي والوسائل التعليمية/ طرق التدريس، والتقويم. بناء على ما سبق ذكره يمكن القول إن تطوير المنهج الدراسي يكون ناجحا بشكل جيد جيد إذا كان مصمما بشكل جيد أيضا، يعني هناك صلة وثيقة بين التخطيط والتنفيذ. ولذلك، إصلاح

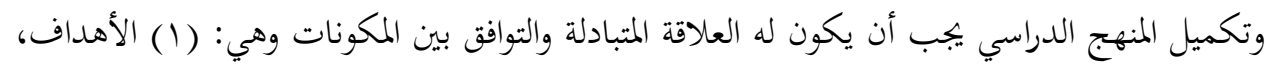

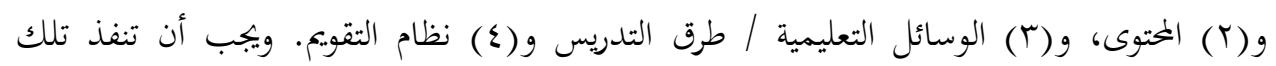
المكونات لتحقيق النتائج المنشودة.

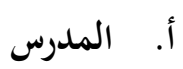
ظهرت النتيجة أن المدرسين لم يخططوا التدريس قبل العمل، أي صياغة المقررات الدراسية

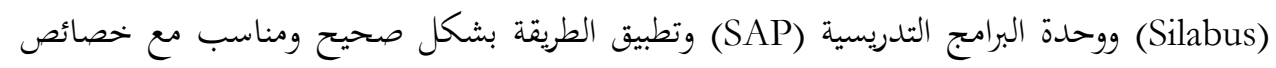

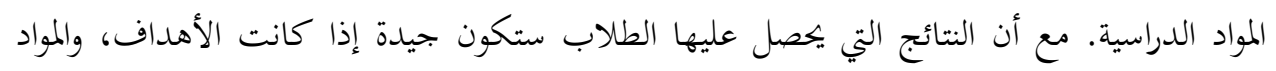
الدراسية، والوسائل التعليمية / طرق التدريس، ونظام التقويم عقدا تعليميا مع الطلاب ليهتموا بها

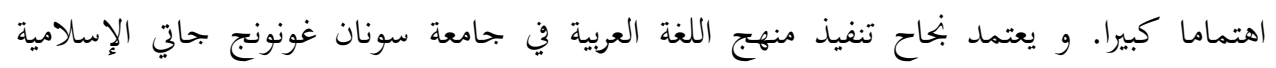

$$
\text { الحكومية باندونج على خصائص مدرسيها الذين يتصفون ما يلي : }
$$

ا. أن يصيغ المدرس خطة التدريس بشكل جيد من خلال صياغة المقررات الدراسية (Silabus)

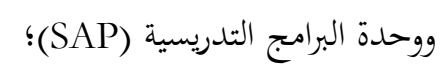

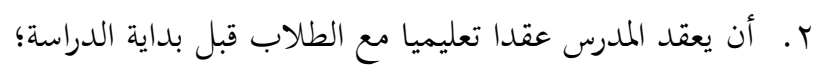

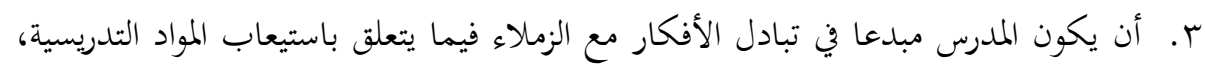

$$
\text { وطرق التدريس، وما إلى ذلك؛ بلكون }
$$

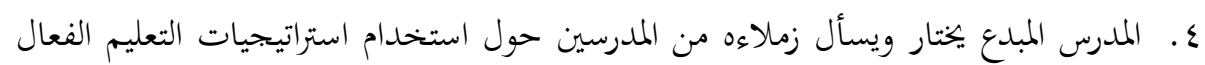

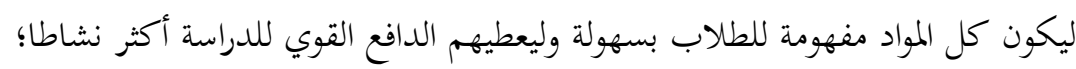

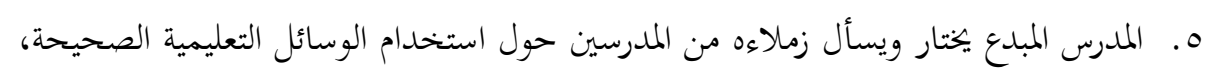

$$
\text { وذلك ليعطي الطلاب الدوافع القوية تجاه التعلم؟ }
$$

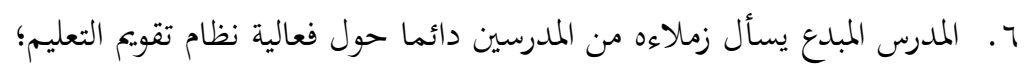

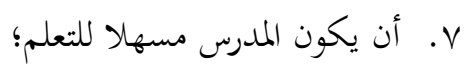


^. أن يجري المدرس عملية التقويم ليس مقتصرا على نتائج التعلم فقط، ولكن يركز أيضا إلى

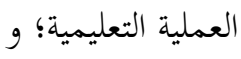

9. أن تكون ثقافة المدرسين واسعة حول تطويرالمنهج الدراسي بحيث يكون عنده شيء دينامي

ويتناسب دائما مع ديناميات المجتمع وتطور العلوم والمعرفة والتكنولوجيا.

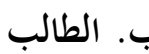

المدرس المؤهل يؤثر في الطلاب أكثر نشاطا وأكثر تقدما، وأكثر إبداعا في عملية التعليم. أما

مواصفات هذه الحالة ما يلي:

1. أن يكون الطلاب أكثر نشاطا لأن المدرسين يستخدمون خطة التدريس

r. أن يكون الطلاب أكثر حماسا ونشاطا ومنضبطا، وأعدوا أنفسهم إعدادا كاملا لأن

المدرسين يعقدون عقد التعلم عقدا واضحا؛

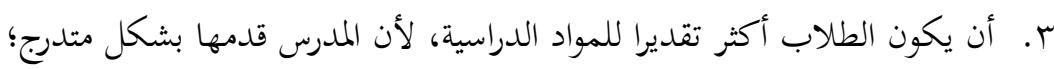

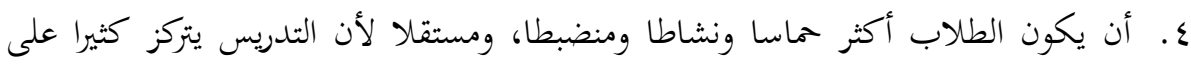

$$
\text { تحربة التعلم؛ }
$$

ه. . أن يكون الطلاب أكثرفعالا وإبداعا في عملية التعلم لأن وظيفة المدرس بحرد الميسر؛ و 7. أن يكون الطلاب نشيطين جدا ومبدعين في عملية التعلم وذلك لأن نظام التقويم المستخدم

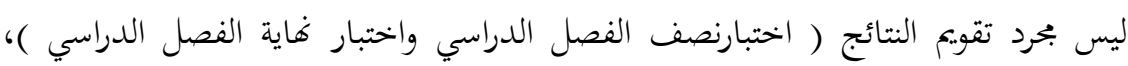

$$
\text { ولكن أيضا في عملية التعلم ( القائم على الفصول الداسية ). }
$$

فعالية المنهج الدراسي المطور في تحسين تدريس اللغة العربية في جامعة سونان غونونج جاتي الإسلامية الحكومية باندونج

يكون دور المدرسين مهما جدا في تطوير المنهج الدراسي، ولا سيما في تحديد الرؤية والرسالة

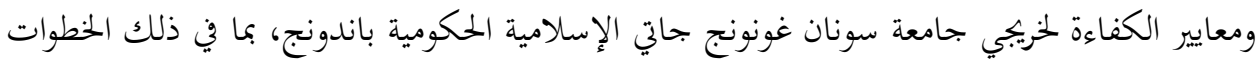
التالية لإعداد المواد الدراسية. وهذا النشاط ليس بحرد وظيفة المدرسين بل سيتم تطبيقها على جميع

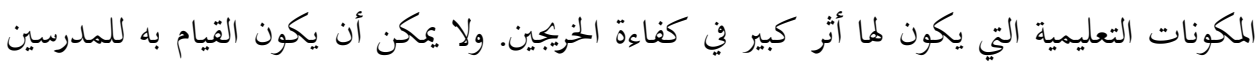

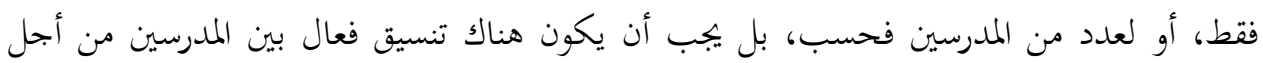
صياغة مضمون وإعطاء المداخلات من كل واحد منهم إلى الآخر. 


$$
\text { أـ ـعالية المنهج الدراسي المطور في ترقية دوافع تعلم الطلاب }
$$

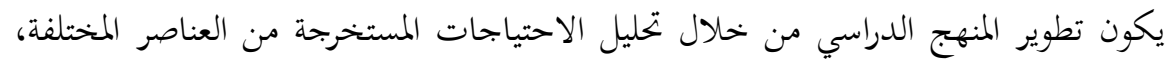

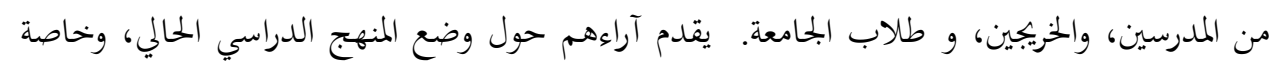

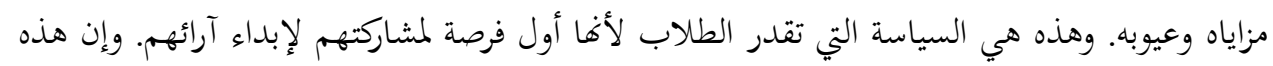

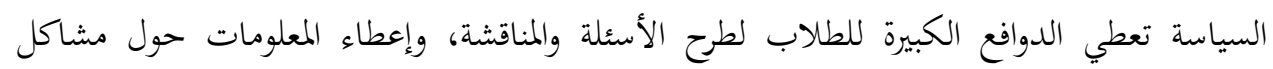

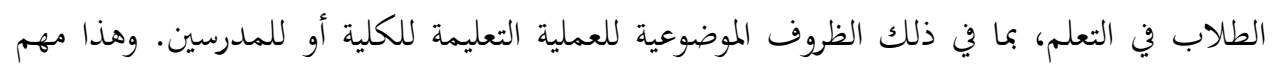
جدا، لأفم الأهداف الرئيسية للمنهج، واقترحاقم مهمة جدا لإجراء الدراسة والتأمل من أجل تحسين نوعية التعليم. العملية التعليمية تركز على تحصيل كفاءة الطلاب. وتحصيل كفاءة الطلاب، موجه إلى نتائج

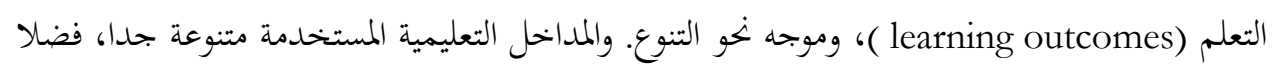
عن أساليب وطرق التدريس .المدرس ليس المصدر الوحيد للتعلم، و العنصر الآخر الذي يفيد للتعلم

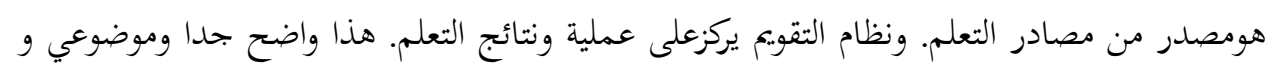

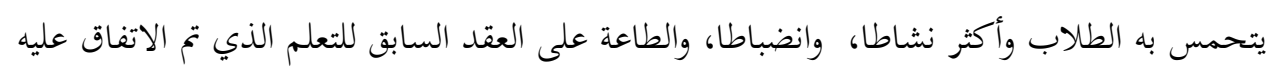

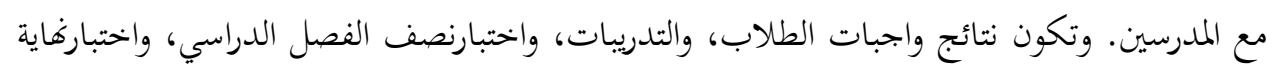

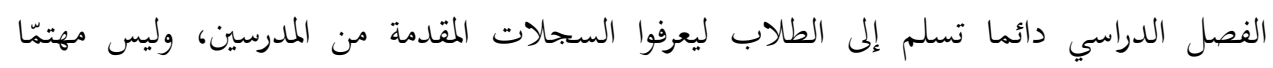

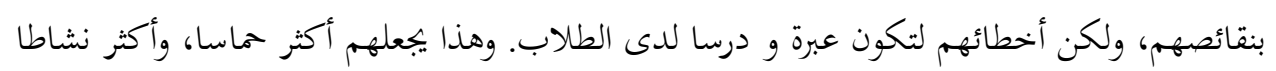
وانتقادا في التعلم (للسؤال والجواب)، وأكثر محاولة لبحث المعلومات من عدة مصنئ مصادر التعلم، وأكثر

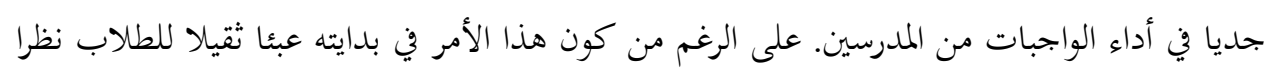

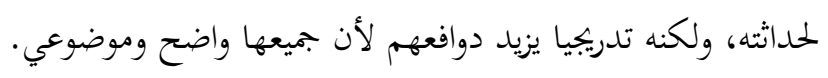

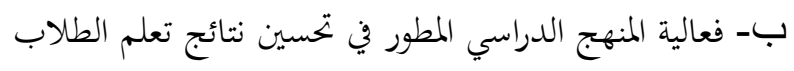

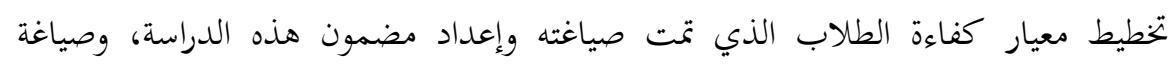

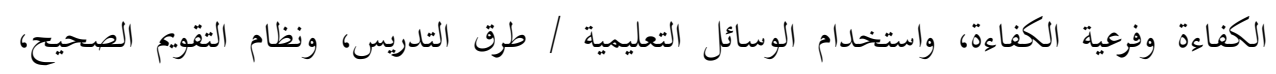

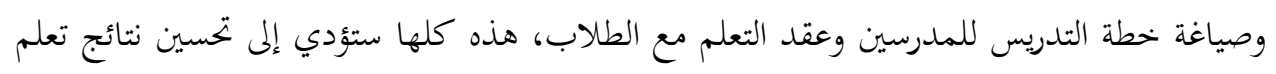
الطلاب. كما أن القيام بالاختبار القبلي، ثم إجراء الدراسة، وينتهي بالاختبارالبعدي يبين تطور

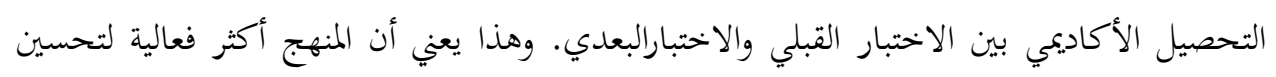
نتائج تعلم الطلاب. 


$$
\text { ج- فعالية المنهج الدراسي المطور في تحسين أداء المدرسين }
$$

كما تبين من نتائج البحث أن أداء مدرسي اللغة العربية في جامعة سونان غونونج جاتي

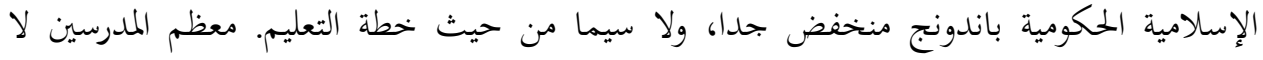
يتعودون على وضع المقررات الدراسية (Silabus) ووحدة البرامج التدريسية (SAP). وهذا يوضح أن معظم المدرسين لا يخطط التعليم. في هذه الدراسة، وفقا لوظيفة المدرسين، يطلب منهم صياغة الأهداف، والمواد الدراسية، والاستراتيجيات / طرق التدريس، والتقويم. وفي العملية التعليمية، يصوغ المدرس خطة التعليم في شكل ملئه

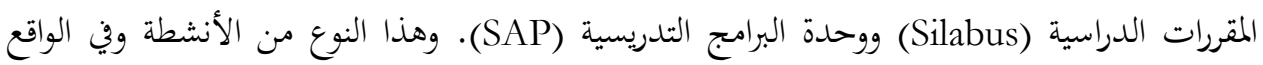
جزء صغير من وظيفة المدرسين المنصبة في خدمة الجامعة الثلاثة (Tridarma perguruan tinggi)، أي على مستوى التعليم. وهذا يعني أن المدرسين لا يعتبرنّ هذا الأمر عبئا ثقيلا يجب علي عليهم حمله لأنه جزء من وظيفتهم. ويكون هذا الجحانب رقما واحدا في خدمات الجامعة الثلاث (Tridarma). وقبل بداية التدريس، يجب على المدرسين وضع خطة تعليمية بشكل ناضج وواضح ( المقررات

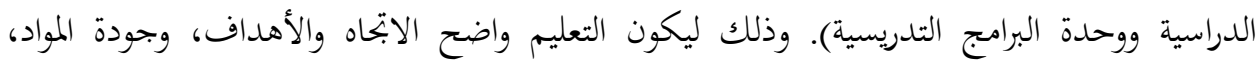
والطرق، والوسائل، والتقويم، والنتائج. وقبل إجراء عملية التعليم، يجرى على الطلاب الاختبار القبلي، وذلك لمعرفة قدرة الطلاب. بعد ذلك يجرى عليهم الاختبار البعدي لمعرفة تطور قدرة الطلاب الأكاديمية بعد عملية التعليم. ومعرفة تغير سلوكهم هل يدل على نتائج ملموسة أم لا.

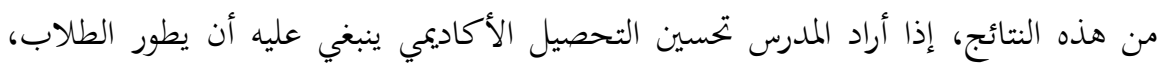

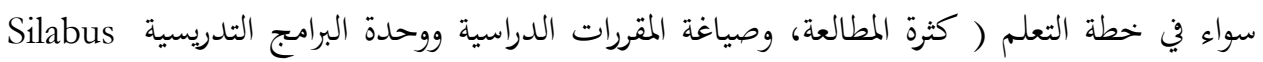
dan SAP/ الطريقة الجيدة و استيعاب المادة.

\section{الظروف الموضوعية لمنهج اللغة العربية المطور في جامعة سونان غونونج جاتي الإسلامية} الحكومية باندونج إستنادا إلى نتائج البحث، يتضح أن منهج متطلبات الجامعة لمادة اللغة العربية في جامعة سونان غونونج جاتي الإسلامية الحكومية باندونج القائم الآن لم يملك عملية التطوير الصحيح. هذا المنهج لا

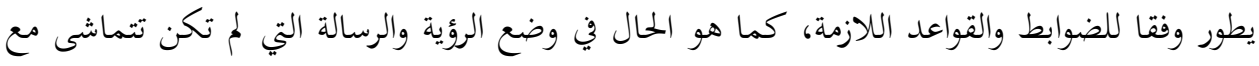


رؤية ورسالة جامعة سونان غونونج جاتي الإسلامية الحكومية باندونج؛ ومعيار كفاءة الخريجين وتحديد

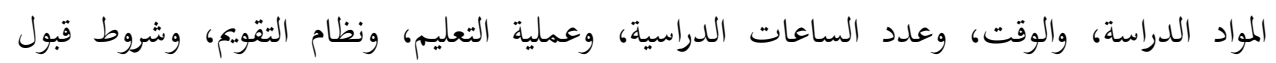

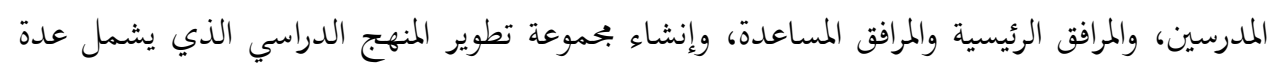
الجماهير / عناصر.

وبناء على ذلك، وضع منهج اللغة العربية المكثف في جامعة سونان غونونج جاتي الإسلامية

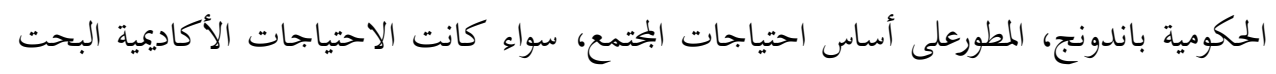

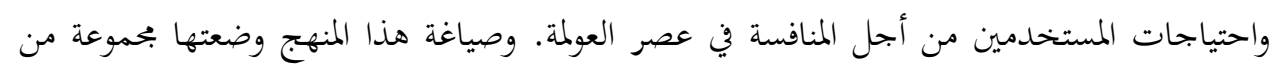

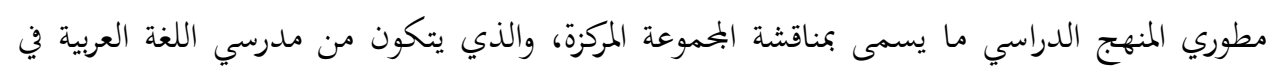

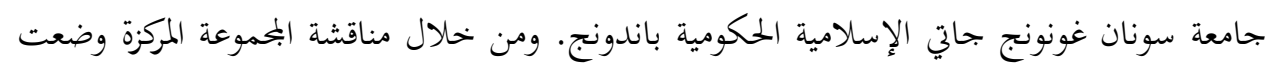

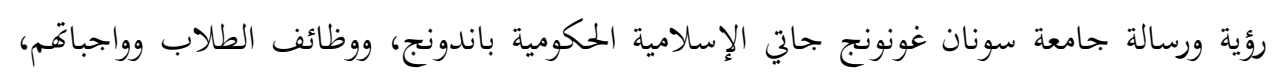

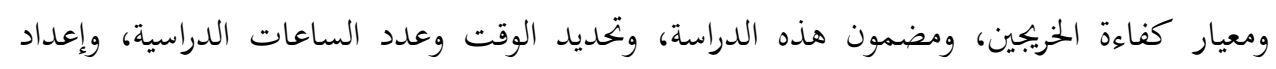

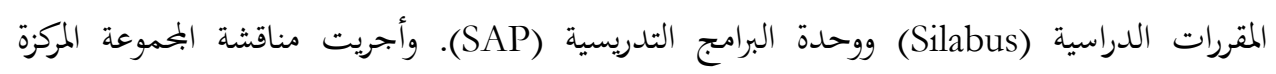
على ثلاث مراحل من أجل التحقق من صحة المنهج الذي تتم صياغتها. أما خطواتها مايلي: (FGD)

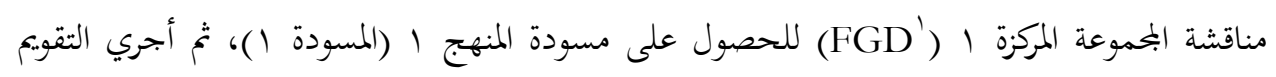

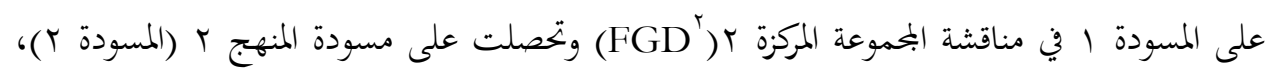

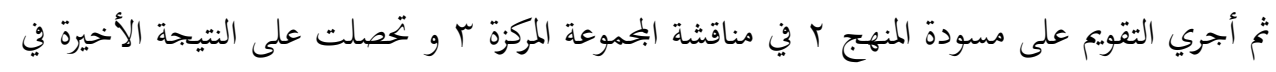

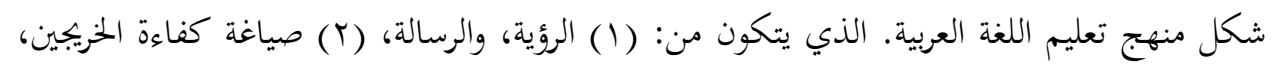

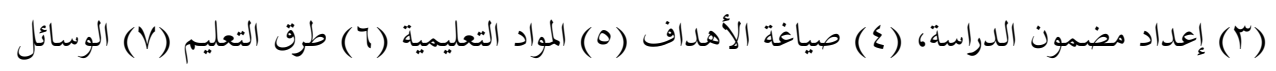

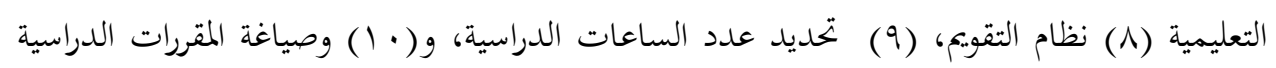
ووحدة البرامج التدريسية / (Nilabus dan SAP).

\section{الفرق بين المنهج المستخدم حاليا والمنهج الجديد بعد التطوير}

لمزيد من تفاصيل الفرق بين المنهج المعمول به الآن والمنهج الجديد المطور به يمكن النظر إلهويد إليه

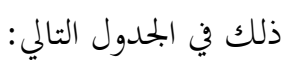

\begin{tabular}{|c|c|c|}
\hline $\begin{array}{c}\text { المنهج الدراسي الجديد المطور به } \\
\text { النتائج النطوير) }\end{array}$ & المنهج الدراسي الحالي الآن & 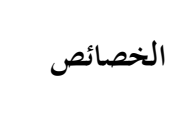 \\
\hline التناسب مع المعهد العالي للعلوم الإسلامية والجامعة & غير محددة & 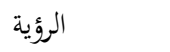 \\
\hline
\end{tabular}




\begin{tabular}{|c|c|c|}
\hline $\begin{array}{c}\text { المنهج الدراسي الجديد المطور به } \\
\text { النتائج التطوير) }\end{array}$ & المنهج الدراسي الحالي الآن & الخصائص \\
\hline الإسلامية الحكومية & & \\
\hline الإسلامية الحكومية مع المعهد العالي للعلوم الإسلامية والجامعة & غير محددة & الرسالة \\
\hline - - تحمليل الاحتياجات & غير محدد & الخرياركفاءة \\
\hline - - - على أساس SKL للى أساس معيار كفاءة مواد اللغة العربية التابعة & غير محدد & لمعيارالكفاءة \\
\hline - - - تحليل الاحتيادا إلى بحموعة مطوري المنهج الراسي & غير محددة & الأهداف \\
\hline - تتماشى مع الأهداف المرجوة & الكتاب المقرر & 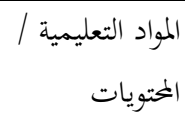 \\
\hline الانتقائية / التوليفية & غير محددة & الطريقة \\
\hline - - وضعت الوسائل المتعددة & غير محددة & 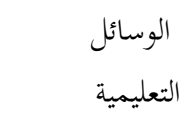 \\
\hline - - - الاختبار القبلي، الاختبار التكويني، الاختبار & 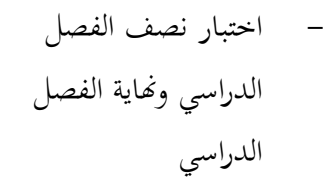 & 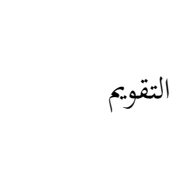 \\
\hline
\end{tabular}

\section{نتائج تنفيذ المنهج الجديد بعد النطوير في غرفة الدراسة}

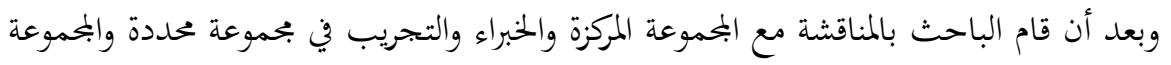
الأوسع نطاقا والتحقق من صحته فقام الباحث بتحليل بيانات نتائج دراسة اللغة العربية للطالبات

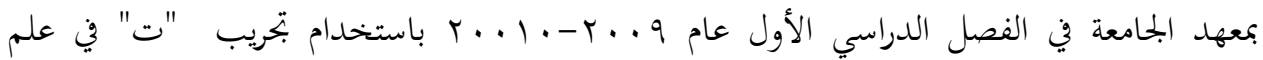
الإحصاء (SPSS versi 19) الحاصل على أن تنفيذ المنهج الجلديد في الفصل يدل على النتائج المرغوب فيها أى أن تطور النتائج من الاختبار القبلي إلى الاختبار البعدي في الفصل التجريبي بين r r 
Vo, Y (9 . , • 1) هذه النتيجة تكون مدخل النقاط لمحاولة تطوير منهج تعليم اللغة العربية في المستقبل وبمعنى

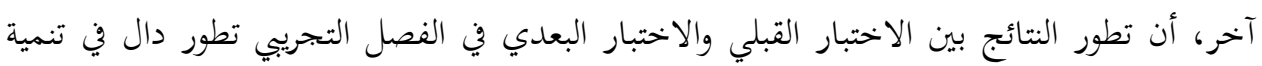
نتائج دراسة الطلبة.

النتيجة

وبعد أن تم البحث، استتج الباحث أن لنمط منهج اللغة العربية الذي تم وضعه وتطويره

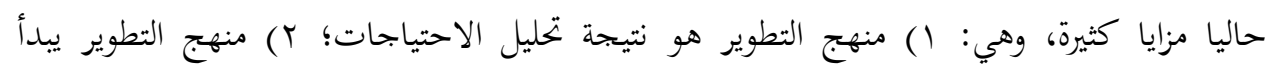
بصياغة الرؤية والرسالة، والمساهمات، والهدف وصياغة المنهج ووحدة برنامج المحاضرة، وصياغة الوسائل والطرق التعليمية و نظام التقويم؛ ؟) إمكانية تطوير المهارات الجحديدة التي لم تكن موجودة في المنهج

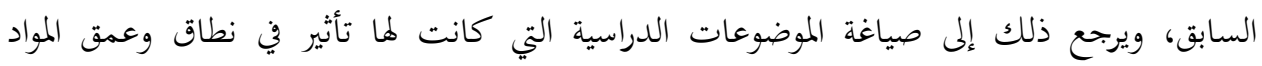
الدراسية من مادة الدراسة المطورة؛ ؟) والمقررات الدراسية (silabus) التي تحتوي على معلومات كاملة

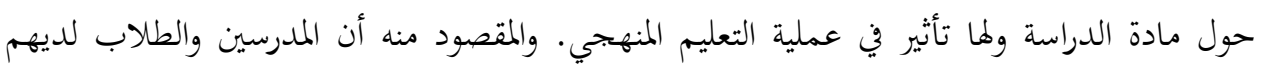
أهداف معينة على حد سواء، ويمكنهم من تطوير الأنشطة وفقا للكفاءات المطلوب تحقيقها، وبحارب التعليم التي تم تطويرها من خلال مختلف المداخل أو الاستراتيجيات، أو الطرق، والمصارد التي يمكن ونئن تفعيلها، ونظام التقويم المستخدم؛ و 0) منهج التطوير يوفر مزيدا من الوضوح في تحقيق الهدف النهائي،

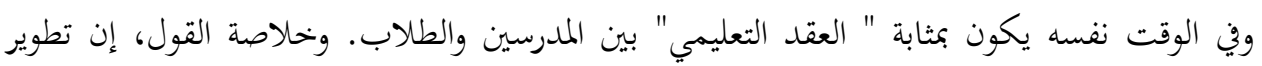

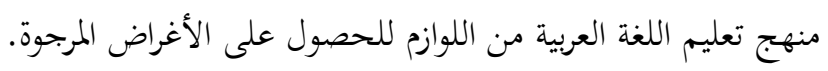

البدري، كمال إبراهيم، 999 19، مذكرة طرائق تدريس اللغة الأجنبية، جاكرتا: معهد اللغة العربية والعلوم الإسلامية

عزيز بحدي إبراهيم، . . . ب، دراسات في المنهج التربوي المعاصر، القاهرة: مكتبة الأبخلو المصرية

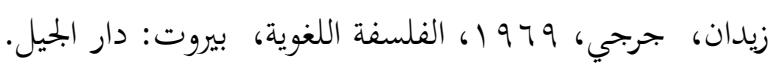

Abdurrahaman, Maman. 2006. "Upaya Peningkeatan Hasil Belajar Nahwu Melalui Quantum Learning, Program Studi Pendidikan Bahasa dan Seni Universitas Pendidikan Indonesia Bandung" Hasil Penelitian.

Alwasilah, A. Chaedar dan Abdullah Khobir. 2003. Revitalisasi Pendidikan Bahasa, Bandung: CV. Andira Bandung.

Alwasilah, A. Chaedar. 2008. Pokoknya Kualitatif, Dasar-dasar Merancang dan 
Melakukan Penelitian Kualitatif, Bandung: PT. Pustaka Jaya dan Pusat Studi Sunda.

Bloom, Benyamin. 1976. Human Characteristics and School Learning, New York: McGraw-Hill Book Company.

Hamalik, Umar. 1993. Evaluasi Kurikulum, Bandung: PT. Rosda Karya.

Hasan, S. Hamid. 2008. Evaluasi Kurikulum, Bandung: PT. Remaja Rosda Karya.

Lucas, Gene, at. Al. 1977. Exploring Teaching Alternatives, Bergers Publisers Company, Mineapolis,

Mansyur, Agus Salim. 2007. "Pengembangan Kurikulum Prodi BSI Fakultas Adab dan Humaniora UIN Sunan Gunung Djati Bandung”, Disertasi UPI Bandung.

Miller, J.P. \& Seller, W. 1985. Curriculum: Pespectives and Practices, New York and London: Longman.

Oliva, Peter F, tt. Developing the Curiculum, Third Edition, Harper Collin Publishers.

Sujana, Nana. 1988. Pembinaan dan Penegmbangan Kurikulum di Sekolah, Bandung: Sinar Baru Algensisndo.

Sukmadinata, Nana Syaodih. 2006. Pengembangan Kurikulum Teori dan Praktek, Bandung: PT. Remaja Rosda Karya.

Taba, Hilda. 1962. Curriculum Development. Theory and Practices. New York: Harcourt, Brace and Worl, Inc. 

Ucapan terima kasih yang sebesar-besarnya disampaikan kepada Mitra Bebestari yaitu:

Suwito, UIN Syarif Hidayatullah Jakarta

Martha Chaterine Beck, Lyon College, USA

Agus Nuryatno, UIN Sunan Kalijaga Yogyakarta

Khoirun Niam, IAIN Sunan Ampel Surabaya

Jajat Burhanudin, UIN Syarif Hidayatullah Jakarta

Jamaludin Darwis, IAIN W ali Songo Semarang

Fuad T. Wahab, UIN Sunan Gunung Djati Bandung

Jamaluddin, IAIN Sulthan Thaha Saifuddin Jambi

Farid Wajdi Ibrahim, IAIN Ar Raniry Banda Aceh

yang telah berkenan membantu dalam menelaah ulang naskah pada volume XXVII No. 2 2012/1433. 